\title{
Carvedilol for prevention of variceal bleeding: a systematic review and meta-analysis
}

\author{
Konstantinos Malandris a, Paschalis Paschos ${ }^{\mathrm{a}, \mathrm{b}}$, Anastasia Katsoulaa , Apostolos Manolopoulos ${ }^{\mathrm{a}}$, \\ Panagiotis Andreadis ${ }^{a}$, Maria Sarigianni ${ }^{a}$, Eleni Athanasiadou ${ }^{a}$, Evangelos Akriviadisc, \\ Apostolos Tsapas ${ }^{\mathrm{a}, \mathrm{d}}$
}

Aristotle University of Thessaloniki, Thessaloniki, Greece; Papageorgiou Hospital, Thessaloniki, Greece; University of Oxford, UK

Abstract

${ }^{a}$ Clinical Research and Evidence-Based Medicine Unit, Second Medical Department, Aristotle University of Thessaloniki, Thessaloniki,

Greece (Konstantinos Malandris, Paschalis Paschos, Anastasia Katsoula, Apostolos Manolopoulos, Panagiotis Andreadis, Maria Sarigianni, Eleni Athanasiadou, Apostolos Tsapas); ${ }^{b}$ First Department of Internal Medicine, "Papageorgiou" Hospital, Thessaloniki, Greece (Paschalis Paschos); 'Fourth Department of Internal Medicine, Aristotle University of Thessaloniki, Thessaloniki, Greece (Evangelos Akriviadis); 'Harris Manchester College, University of Oxford, Oxford UK (Apostolos Tsapas)

Conflict of Interest: None

Correspondence to: Konstantinos Malandris, MD, Clinical Research and Evidence-Based Medicine Unit, Second Medical Department, Aristotle University Thessaloniki, Konstantinoupoleos 49, 54642, Thessaloniki, Greece, e-mail: malandrk@auth.gr

Received 16 December 2018; accepted 4 February 2019; published online 12 March 2019

DOI: https://doi.org/10.20524/aog.2019.0368

\section{Introduction}

Esophageal varices (EV) are found in approximately $30 \%$ of patients with cirrhosis at the time of first diagnosis [1]. EV bleeding is a life-threatening complication of portal hypertension, responsible for almost $80 \%$ of all bleeding episodes in patients with cirrhosis [2]. The annual rate of variceal hemorrhage ranges from 5-15\% [3,4], depending on the presence of several risk factors [5]. In addition, variceal rebleeding occurs at a rate of $63 \%$ within a time frame of 1-2 years [6]. Despite the improvement in management procedures, EV hemorrhage still accounts for high mortality rates [7].

Guidelines support the use of non-selective beta-blockers (NSBBs) such as propranolol or nadolol for prophylaxis of variceal bleeding. Carvedilol is a potent beta-blocker, with mild anti-alpha 1 adrenergic activity that causes downregulation of 
intrahepatic resistance and an additional decrease in hepatic venous pressure gradient (HVPG), that has been used for primary prophylaxis of variceal hemorrhage $[8,9]$. Evidence suggests that only $40 \%$ of patients treated with NSBBs reach appropriate HVPG levels [10,11]. The use of carvedilol has been associated with hemodynamic regulation in 56\% of propranolol non-responders [11]. However, the efficacy of carvedilol compared with standard-of-care approaches remains to be demonstrated. To provide a thorough summary of existing evidence, we performed a systematic review and meta-analysis investigating the efficacy and safety of carvedilol for primary or secondary prophylaxis of variceal hemorrhage in patients with cirrhosis.

\section{Materials and methods}

This systematic review and meta-analysis was conducted in compliance with a pre-specified protocol and according to the Preferred Reporting Items for Systematic reviews and Meta-analyses (PRISMA) statement (Supplementary material, Table S1) [12].

\section{Study eligibility criteria}

We included all randomized controlled trials (RCTs) with a follow-up duration of at least 6 months, comparing carvedilol with placebo or any active intervention, either alone or in combination, in adults with cirrhosis and EV, irrespective of any previous history of variceal bleeding. We applied no limitations based on language, date or type of publication.

\section{Identification and selection of the studies}

We compiled a search strategy using relevant terms for carvedilol and the condition of interest (EV and variceal bleeding) (Supplementary material, Table S2). We systematically searched Medline, Embase and the Cochrane central register of controlled trials for relevant trials up to May 2018. We also screened conference proceedings from United European Gastroenterology (UEG) Week, American Association for the Study of Liver Diseases (AASLD), European Association for the Study of the Liver (EASL), Digestive Disease Week (DDW), and the American College of Gastroenterology annual meetings from 2010-2017. Finally, we scanned clinicaltrials. gov for additional completed trials.

All records retrieved from major electronic databases were imported into reference management software (EndNote X7, Thomson Reuters, New York City, New York). After removal of duplicates, references were screened for eligibility by 2 independent reviewers ( $\mathrm{KM}$ and $\mathrm{AK}$ ), firstly at title and abstract level and subsequently at full-text level. Eligible trials identified in gray literature were juxtaposed against records from electronic databases. Screening was performed using online software (Covidence, Veritas Health Innovation Ltd, Melbourne, Australia). Any discrepancies during the screening process were resolved by consensus.

\section{Data collection process}

Two reviewers (KM and AM) independently performed data extraction. We utilized a predesigned extraction form to abstract data from eligible trials relating to trial characteristics, participants' baseline characteristics and outcomes of interest. Any disagreements at this stage were settled by a third reviewer (PP). Multiple reports for the same trial were collated in order to maximize the information yield.

\section{Risk of bias in individual studies}

Risk of bias was assessed in duplicate by 2 independently working reviewers (KM and $\mathrm{AP}$ ) using the revised Cochrane risk-of-bias tool (ROB) 2.0 [13]. Any disagreements at this stage were resolved by consensus. The trials were graded as low risk, some concerns, or high risk of bias depending on the evaluation of 5 distinct domains within the tool. These were randomization, deviations from intended interventions, missing outcome data, measurement of the outcome and selection of reported results. Regarding the domain of randomization, evaluation was performed at trial level, whereas all other domains were assessed separately for every outcome. The overall risk of bias of a trial was considered low if all domains were at low risk of bias and high if there was at least 1 domain at high risk of bias or at least 3 domains with some concerns. In any other case a trial was deemed to have some concerns for bias.

\section{Outcome measures}

The primary outcome was the incidence of variceal bleeding, as defined by the authors of each individual study. Secondary efficacy outcomes included all-cause bleeding, all-cause mortality, bleeding-related mortality and incidence of variceal progression from small to large varices. Safety outcomes assessed included incidence of adverse events (AE) (as defined by individual study investigators) and discontinuation due to AE. All outcome measures were synthesized separately for trials assessing the use of carvedilol for primary or secondary prophylaxis, except for the incidence of $\mathrm{AE}$ and withdrawal due to $\mathrm{AE}$.

\section{Data synthesis}

Outcomes are presented as risk ratios (RR) with 95\% confidence intervals (CI). We synthesized data using random effects models. Data from intention-to-treat (ITT) analyses were preferred when available. The threshold of 0.05 was set 
as the cutoff significance value (a) for all analyses. We assessed statistical heterogeneity using the $I^{2}$ statistic, with values lower than $60 \%$ indicating low heterogeneity [14]. We aimed to assess the small-study effect by checking the asymmetry of funnel plots and by performing Egger's test [15]. We performed predefined sensitivity analyses, excluding trials at high risk of bias. We also conducted post-hoc subgroup analysis based on the mean duration of follow up ( $\leq$ or $>12$ months) to verify the robustness of our conclusions. In studies where the duration of follow up was provided as median (range or interquartile range) rather than mean and standard deviation the latter was calculated as described previously $[16,17]$. Statistical analyses were implemented using Review Manager 5.3 [18].

\section{Grading of evidence}

We used the Grading of Recommendations Assessment, Development and Evaluation (GRADE) approach [19] to assess the credibility of our summary estimates. One reviewer (MS) evaluated impression, indirectness, publication bias and risk of bias for all outcomes separately. We used GRADEpro (GRADE Working Group) to generate a summary-of-findings Table.

\section{Results}

\section{Results of search and trial characteristics}

A detailed presentation of the study selection process is depicted in Fig. 1. Our search retrieved 190 records from electronic databases and literature sources. After removal of duplicates, 132 records were screened at title and abstract level and 93 records were excluded. Subsequently, the remaining 39 records were assessed at full text level. Twenty-two records describing 13 [20-32] trials (1598 patients) were finally included in the meta-analysis.

A summary of the main characteristics of the included trials is presented in Table 1. Eight trials were published as full-text manuscripts, whereas the remaining 5 trials were available only in abstract form. Six trials assessed carvedilol for primary prophylaxis of variceal bleeding compared with endoscopic variceal ligation (EVL) [22-25] or propranolol [20-22]. Secondary prophylaxis was evaluated in 6 trials comparing carvedilol with EVL [27,28,32], propranolol [29] or NSBBs plus isosorbide-5-mononitrate (ISMN) [27,31]. One trial compared carvedilol with propranolol for secondary prophylaxis on top of EVL therapy [30]. Only 1 placebo-controlled trial assessed the efficacy of carvedilol for prevention of variceal progression [26]. Mean duration of follow up ranged from 6-26.2 months, while sample size ranged from 25-264 patients. In most trials the mean dose of carvedilol was $12.5 \mathrm{mg} /$ day. Patients' mean age and percentage of men included ranged from 41.7-54.5 years and from 11.4-96.7\%, respectively. Baseline information regarding Child-Pugh class, etiology of cirrhosis, size of varices and presence of gastric varices were poorly reported. Most patients had F2 EV with viral related cirrhosis, and had Class B disease according to the Child-Pugh classification. Concomitant gastric varices were present in 98 patients in total (5 trials [22,24-26,31]).

\section{Risk-of-bias assessment}

The risk-of-bias assessment for the primary outcome is summarized in supplemental digital content (Supplementary material, Table S3). Among trials assessing the use of carvedilol for primary prophylaxis, 2 trials were at low risk of bias [24,25], 2 trials were at high risk [20,22], due to a suboptimal description of the randomization process, inadequate blinding, missing outcome data and selection of reported results, while there were some concerns about the remaining 2 trials [21,23], mainly due to poor reporting of the trial's procedures. Among secondary prevention trials, 1 was at low risk of bias [31], whereas 3 trials were at high risk of bias $[27,28,32]$ because of an inadequate description of the randomization process, poor blinding and missing outcome data. Finally, there were some concerns about the overall risk of bias for the remaining 2 trials [29,30], due to missing outcome data and the type of analysis used (per protocol). The risk-of-bias assessment for the secondary outcomes is presented in the supplemental digital content (Supplementary material, Tables S4-S9).

\section{Analysis of primary and secondary outcomes}

\section{Efficacy outcomes}

Carvedilol was as efficacious as EVL (4 RCTs, RR 0.74, 95\%CI $0.37-1.49, I^{2}: 61 \%$ ) or propranolol (3 RCTs, RR 0.76, $95 \%$ CI $\left.0.27-2.14, I^{2} 63 \%\right)$ for the prevention of first variceal bleeding (Fig. 2). There were no differences in the incidence of all-cause and bleeding-related mortality between carvedilol and EVL (2 RCTs, RR 1.06, 95\%CI 0.75-1.50, $I^{2}: 0 \%$ and RR 1.43, 95\%CI 0.55-3.72, $I^{2}: 0 \%$, respectively) or propranolol (1 RCT, RR 1.07, 95\%CI 0.38-3.03, $I^{2}$ : not estimable and RR 0.86 , 95\%CI $0.16-4.67, I^{2}$ : not estimable, respectively) (Fig. 3,4). The risk for the incidence of all-cause bleeding could not be assessed because of a lack of relevant data.

One trial [26] reported a lower incidence of progression from small to large varices in patients treated with carvedilol compared to placebo (RR 0.56, 95\%CI 0.32-0.98). However, there was no difference in the risk for all-cause mortality (RR 0.25 95\%CI 0.06-1.14) and no bleeding episodes were reported in either treatment arm.

For secondary prevention of variceal bleeding, carvedilol was as efficacious as EVL (3 RCTs, RR 1.10, 95\%CI 0.75-1.61, $I^{2}$ : 0\%), propranolol (2 RCTs, RR 0.39, 95\%CI 0.15-1.03, $I^{2}: 0 \%$ ) and NSBBs plus ISMN (2 RCTs, RR 1.02, 95\%CI 0.70-1.51, $I^{2}$ : 22\%) (Fig. 5). Likewise, carvedilol was as efficacious as EVL (1 RCT, RR 0.87, 95\%CI 0.49-1.55, $I^{2}$ : not estimable and RR 4.70, 95\%CI 0.58-37.99, $I^{2}$ : not estimable, respectively) or 


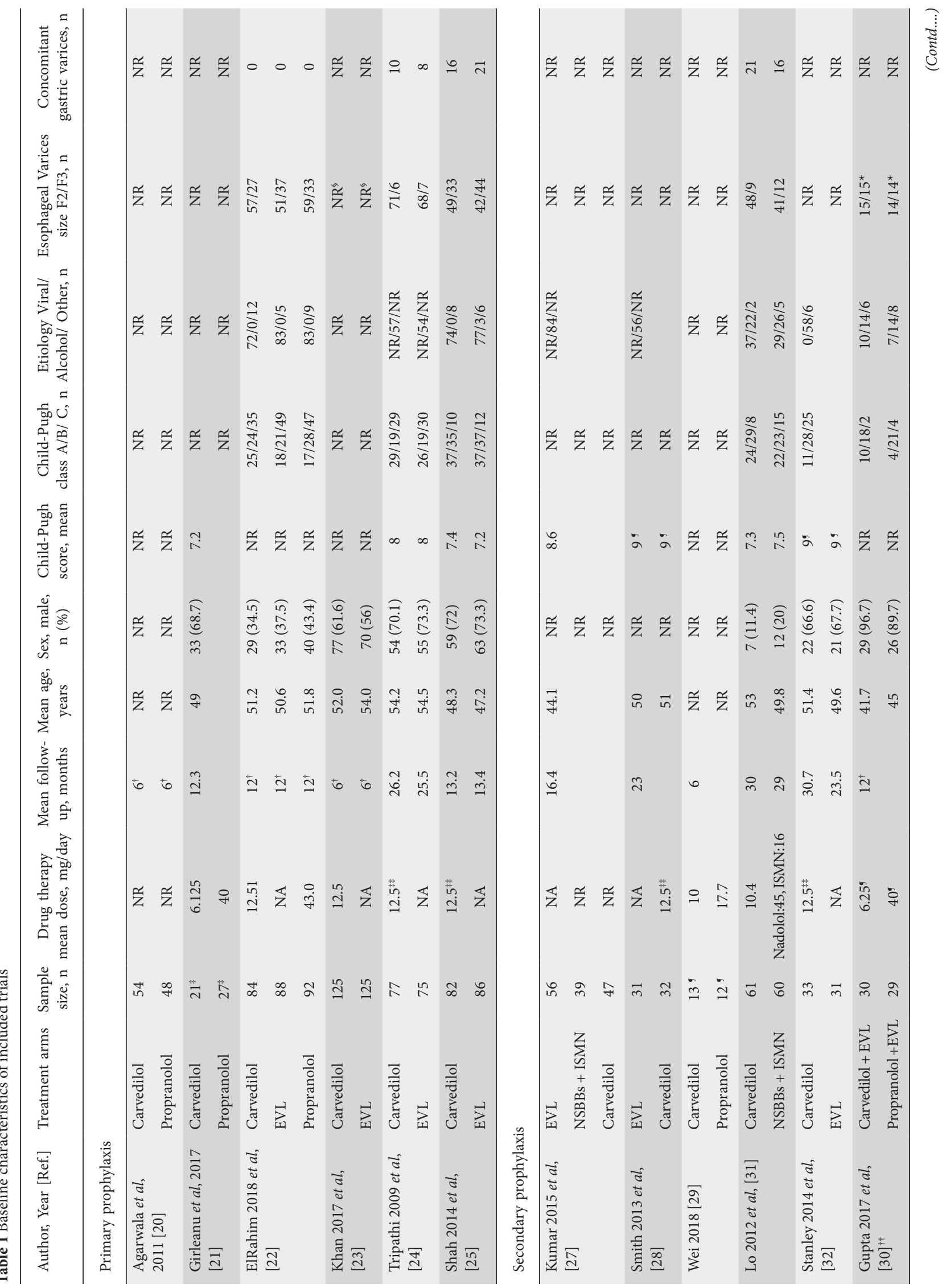




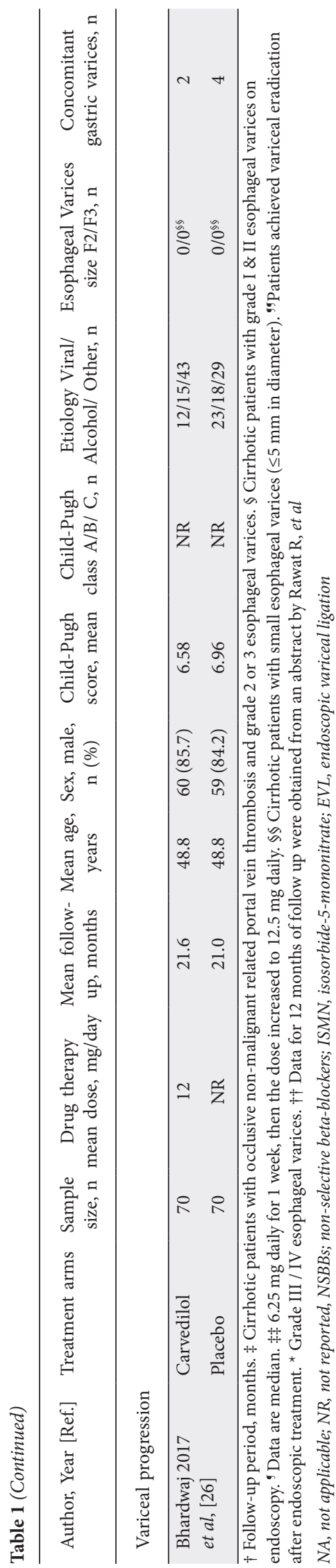

NSBBs plus ISMN (1 RCT, RR 0.98, 95\%CI 0.74-1.31, $I^{2}$ : not estimable and RR 0.66, 95\%CI 0.11-3.79, $I^{2}$ : not estimable, respectively) for prevention of all-cause bleeding and bleedingrelated mortality. Finally, carvedilol reduced the all-cause mortality compared with EVL (3 RCTs, RR 0.51, 95\%CI 0.33$\left.0.79, I^{2}: 0 \%\right)$. However, there was no difference when compared to NSBBs plus ISMN (2 RCTs, RR 0.70, 95\%CI 0.36-1.36, $I^{2}: 24 \%$ ) (Fig. 6).

Results from sensitivity analyses for all efficacy outcomes are presented in the supplemental digital content (Supplementary material, Tables S10-S13). Overall, the results remained unchanged in sensitivity analyses excluding studies at high risk of bias.

Finally, the results for primary prophylaxis were consistent in a subgroup analysis based on duration of follow up $(\leq 12$ or $>12$ months), both against NSBBs (2 RCTs, RR 0.66, 95\%CI $0.13-3.40, I^{2}: 81 \%$ and 1 RCT, RR 0.96, 95\%CI 0.24-3.85, $I^{2}$ : not estimable, respectively) and against EVL (2 RCTs, RR 0.77, 95\%CI $0.19-3.02, I^{2}: 81 \%$ and 2 RCTs, RR 0.70 , 95\%CI 0.27 $1.82, I^{2}: 54 \%$, respectively). We could not perform subgroup analyses for secondary prophylaxis because of a lack of relevant data (all trials comparing carvedilol with EVL or NSBBs plus ISMN had a mean follow-up duration $>12$ months, while all trials assessing carvedilol against NSBBs had a mean followup duration $\leq 12$ months) (Supplementary material, Table S14).

\section{Safety outcomes}

In terms of the incidence of any $\mathrm{AE}$, carvedilol showed no clear difference compared with EVL (5 RCTs, RR 1.99, 95\%CI $0.79-5.02, I^{2}$ : 93\%), NSBB plus ISMN (2 RCTs, RR 0.38 , 95\%CI $0.13-1.07, I^{2}: 74 \%$ ) or propranolol (3 RCTs, RR 0.65, 95\%CI 0.31-1.38, $I^{2}$ : 69\%) (Fig. 7).

Regarding withdrawal due to AE, carvedilol showed a similar risk as both EVL (3 RCTs, RR 2.28, 95\%CI 0.59-8.84, $I^{2}: 30 \%$ ) and propranolol (2 RCTs, RR 2.68, 95\%CI 0.41-17.53, $I^{2}: 0 \%$ ) (Fig. 8). In 1 trial [31], NSBB plus ISMN had a higher risk of withdrawal due to AE compared to carvedilol (RR 0.03, 95\%CI: 0.00-0.43).

In terms of incidence of any $\mathrm{AE}$, carvedilol was associated with a lower risk compared to NSBBs plus ISMN in sensitivity analyses that excluded trials at high risk of bias (Supplementary material, Table S15). For the incidence of withdrawal due to $\mathrm{AE}$, sensitivity analyses excluding studies at high risk of bias generated the same results (Supplementary material, Table S16).

\section{Grade}

Overall, our confidence in the effect estimates for all efficacy and safety outcomes was very low. Substantial heterogeneity, which could not be explained by sensitivity or subgroup analyses, was detected in most of our analyses. Moreover, the number of included studies and the number of events were small. Furthermore, our confidence in the effect estimates was 


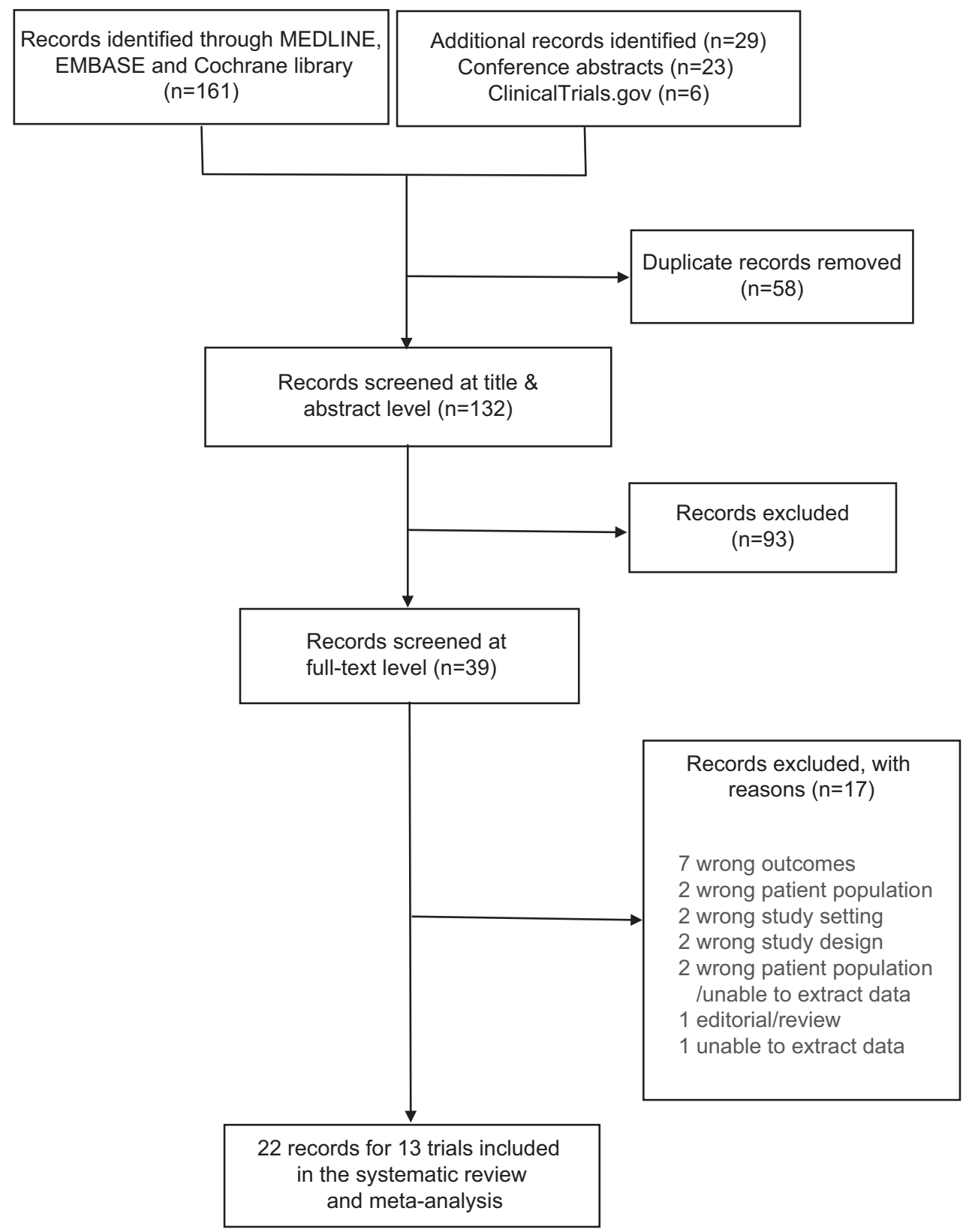

Figure 1 Prisma flow diagram

downgraded because of the large number of trials with some concerns or at high risk of bias, the small sample size, and the inability to assess publication bias due to the limited number of trials (Supplementary material, Table S17-S21).

\section{Discussion}

In this systematic review and meta-analysis, very lowquality evidence suggests that carvedilol has a beneficial effect on the prevention of variceal bleeding in patients with cirrhosis. Limited data from 1 trial indicate that carvedilol may delay the progression from small to large varices. Carvedilol is as efficacious as EVL or NSBBs for primary prevention of variceal bleeding. In addition, very low-quality evidence indicates that carvedilol is as efficacious as propranolol in the prevention of rebleeding after successful variceal eradication with EVL. Finally, carvedilol is well tolerated and has safety profiles comparable with those of other interventions.

The efficacy of carvedilol has been explored in a previous systematic review [33], but this incorporated a limited number of trials and focused mainly on surrogate outcomes related to variceal bleeding. Compared to this meta-analysis, we identified a beneficial effect of carvedilol against EVL on mortality. This could be attributed to the inclusion of 2 


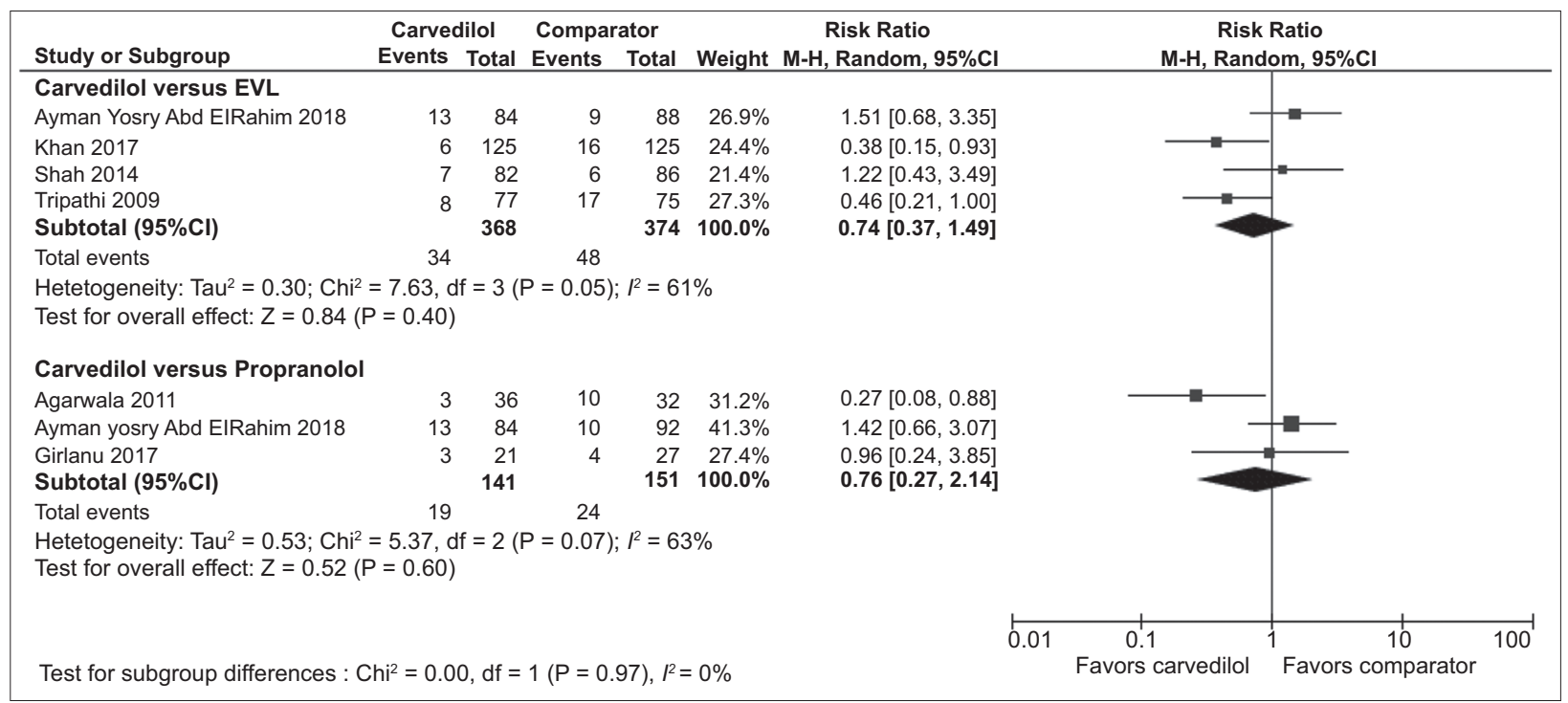

Figure 2 Risk ratio for incidence of variceal bleeding, primary prophylaxis CI, confidence interval; EVL, endoscopic variceal ligation; $M-H$, Mantel-Haenszel

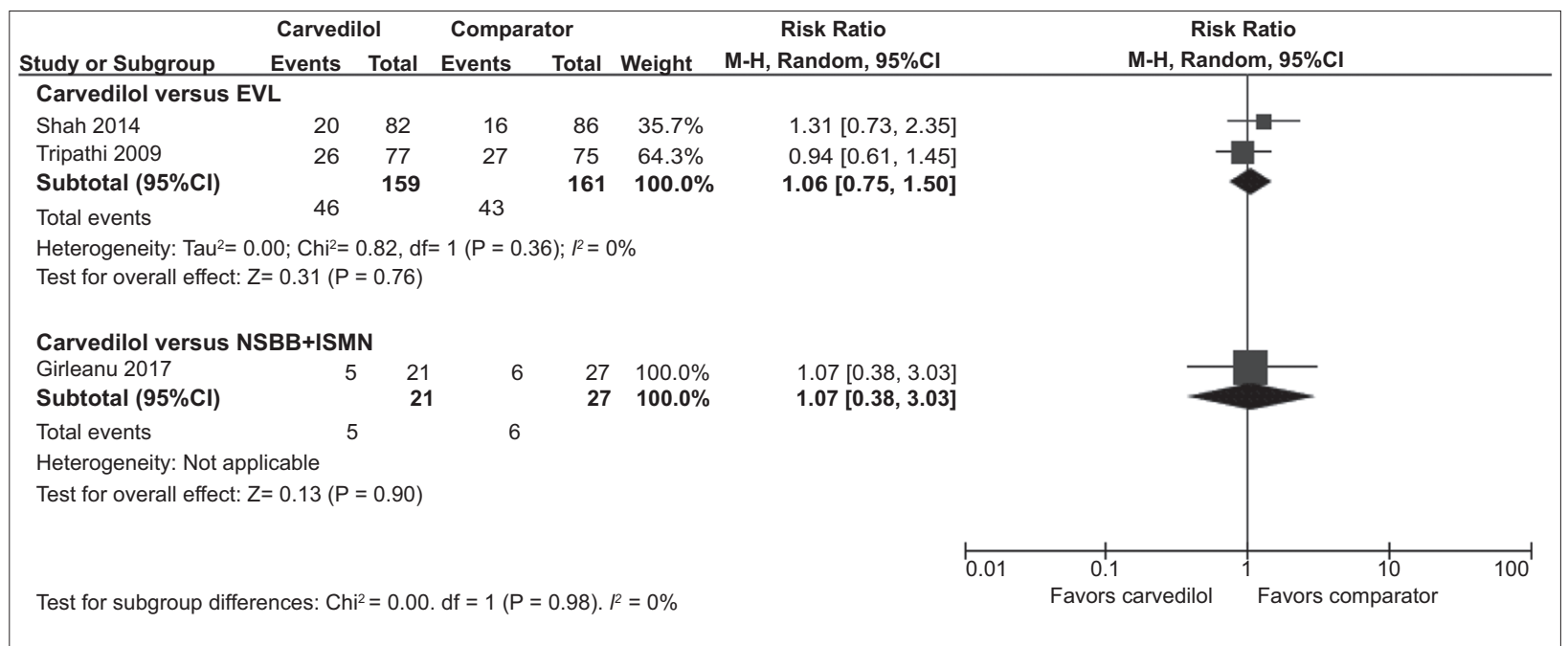

Figure 3 Risk ratio for incidence of all-cause mortality, primary prophylaxis CI, confidence interval; EVL, endoscopic variceal ligation; $M-H$, Mantel-Haenszel

additional trials assessing secondary prophylaxis [27,28] that had better precision. In addition, a recently published Cochrane meta-analysis evaluated the effects of carvedilol compared with the conventionally used NSBBs in patients with cirrhosis [34]. Our findings were in line with the results of the aforementioned meta-analysis in terms of both efficacy and safety-related outcomes. Notably, the Cochrane meta-analysis included RCTs with a duration of at least 1 week and further provided evidence for the ability of carvedilol to decrease HVPG. Under this scope, carvedilol proved more efficacious than traditionally used NSBBs; however, this finding was not accompanied by a difference in the incidence of upper gastrointestinal bleeding. Zacharias et al performed a subgroup analysis based on trial duration by setting the cutoff value at 3 months. This analysis was similar to ours (cutoff value
6 months) and yielded the same conclusion. A major difference between the 2 meta-analyses is that we further evaluated the beneficial and harmful effects of carvedilol compared with EVL. Although EVL is an invasive procedure, it represents the cornerstone in the prophylaxis of variceal bleeding, for either primary or secondary prevention. Consequently, we consider our meta-analysis to be the most comprehensive in terms of existing comparisons.

Hence, our systematic review is the most updated summary of evidence on the efficacy and safety of carvedilol compared to the current standard of care in patients with EV. In addition, we collected and appraised evidence focused on clinically important outcomes, supporting the use of carvedilol in the prophylaxis of variceal bleeding. Further strengths of our work include a thorough literature search 


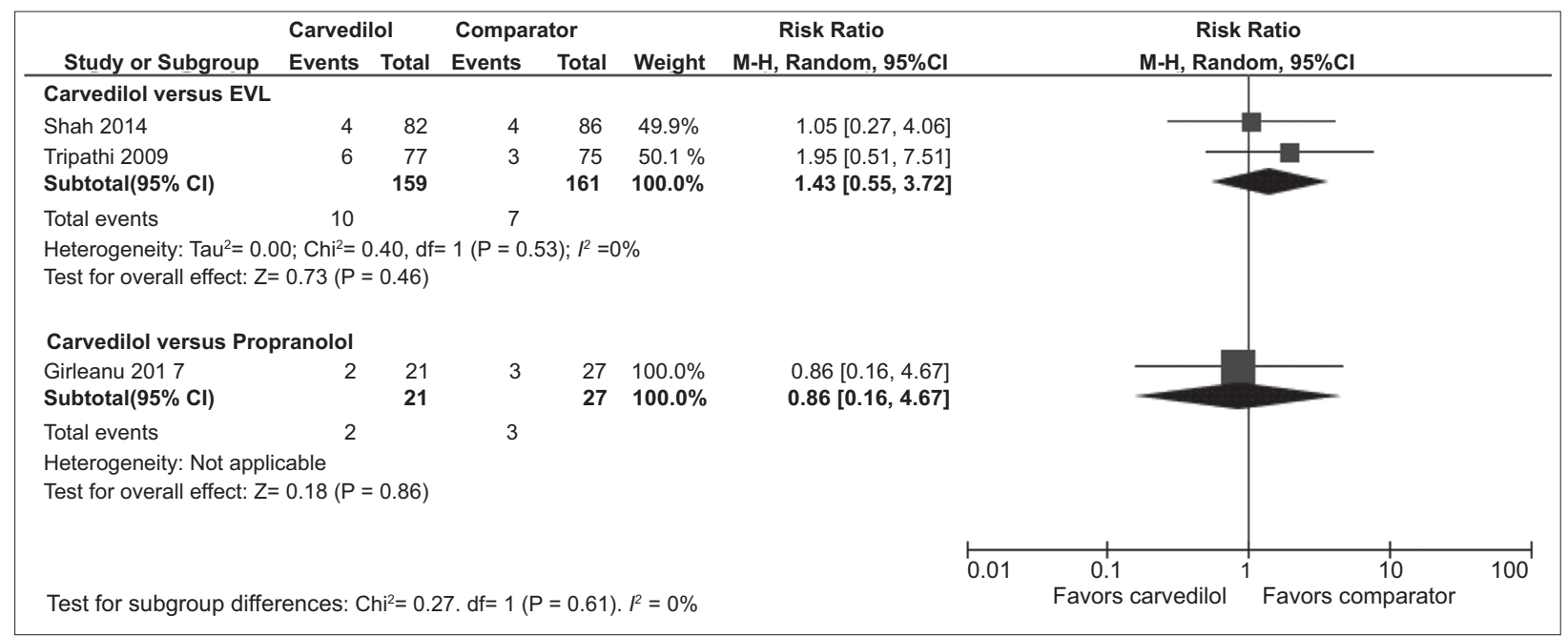

Figure 4 Risk ratio for incidence of bleeding related mortality, primary prophylaxis CI, confidence interval; EVL, endoscopic variceal ligation; $M-H$, Mantel-Haenszel

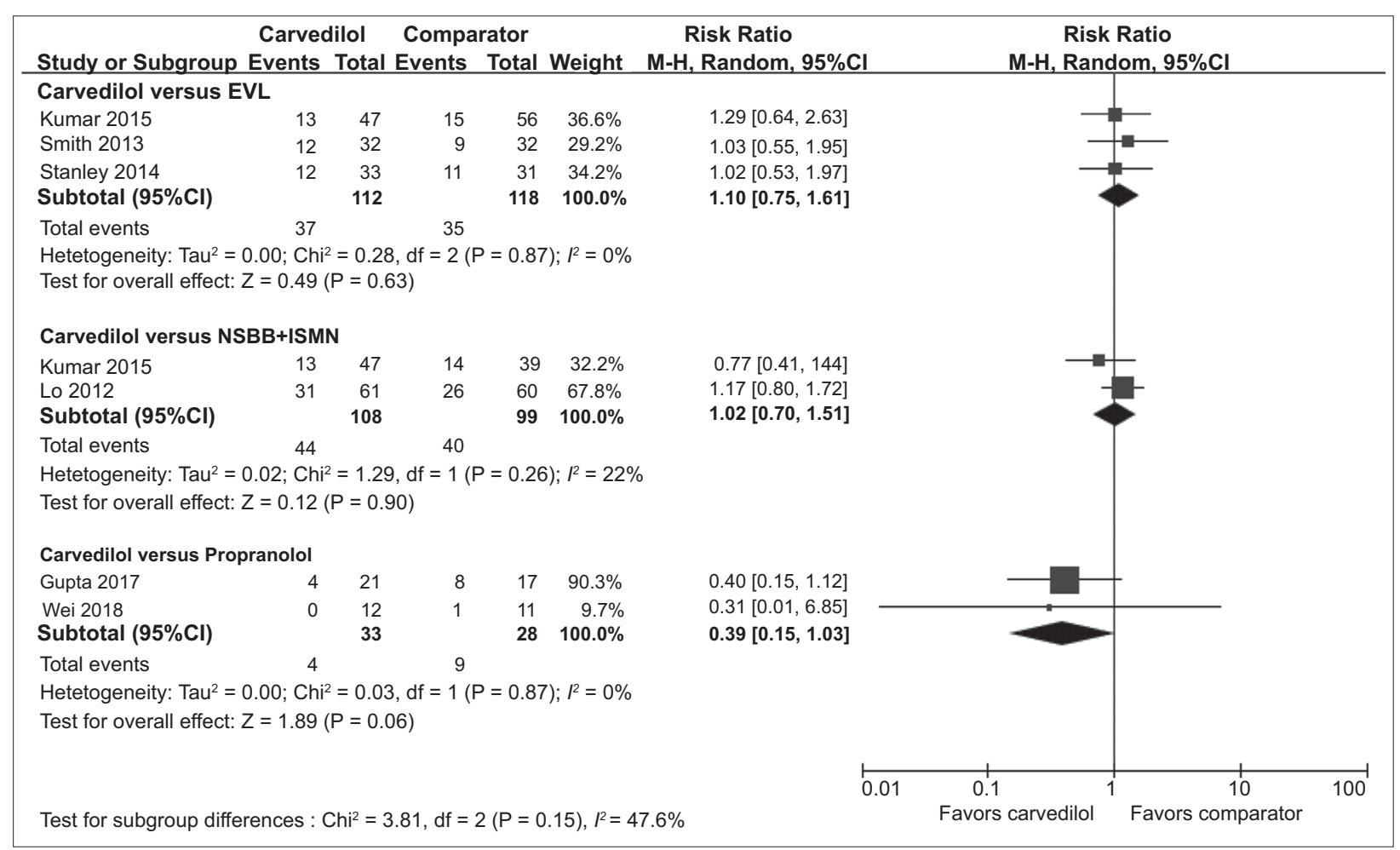

Figure 5 Risk ratio for incidence of variceal bleeding, secondary prophylaxis

CI, confidence interval; EVL, endoscopic variceal ligation; NSBB, non-selective beta-blocker; ISMN, isosorbide-5-mononitrate; M-H, Mantel-Haenszel

both of major electronic databases and of grey literature, without imposing any limitations, from which we extracted data for a variety of clinically important outcomes related to safety and efficacy. We explored the robustness of conclusions by assessing the methodological integrity of included studies, using the most updated methodological tool [13], and we performed multiple sensitivity analyses. Finally, we evaluated the confidence in our estimates using the GRADE approach.
However, certain limitations have to be acknowledged. Despite an exhaustive literature search we identified only 13 eligible studies, almost half of which (38\%) were available only in abstract form. The overall sample size was limited, leading to wide CIs in our summary estimates. The majority of studies were of poor quality, mainly due to suboptimal reporting of the randomization procedures, inadequate blinding (especially when carvedilol was compared with EVL) and missing outcome data. Apart from that, there was a high degree of 


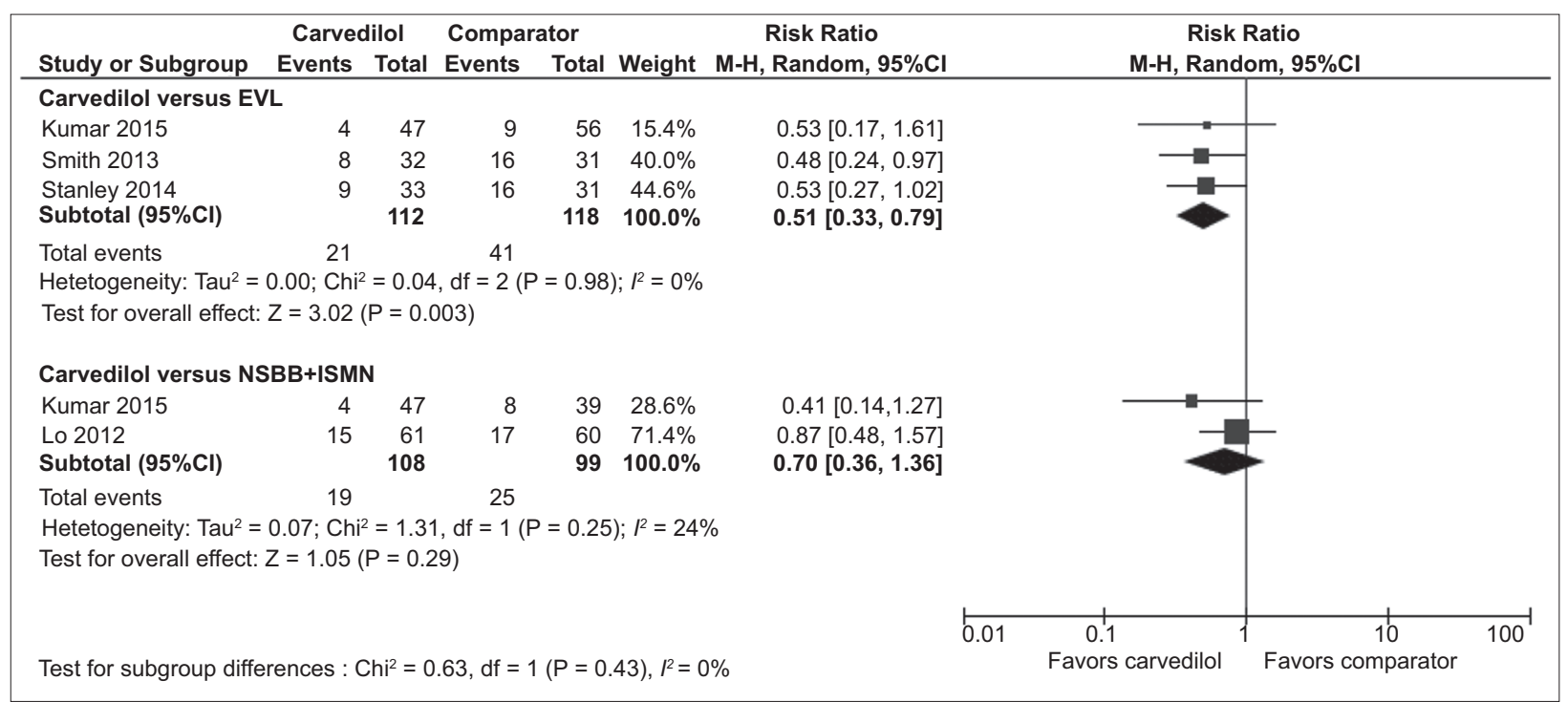

Figure 6 Risk ratio for incidence of all-cause mortality, secondary prophylaxis

CI, confidence interval; EVL, endoscopic variceal ligation; NSBB, non-selective beta-blocker; ISMN, isosorbide-5-mononitrate; M-H, Mantel-Haenszel

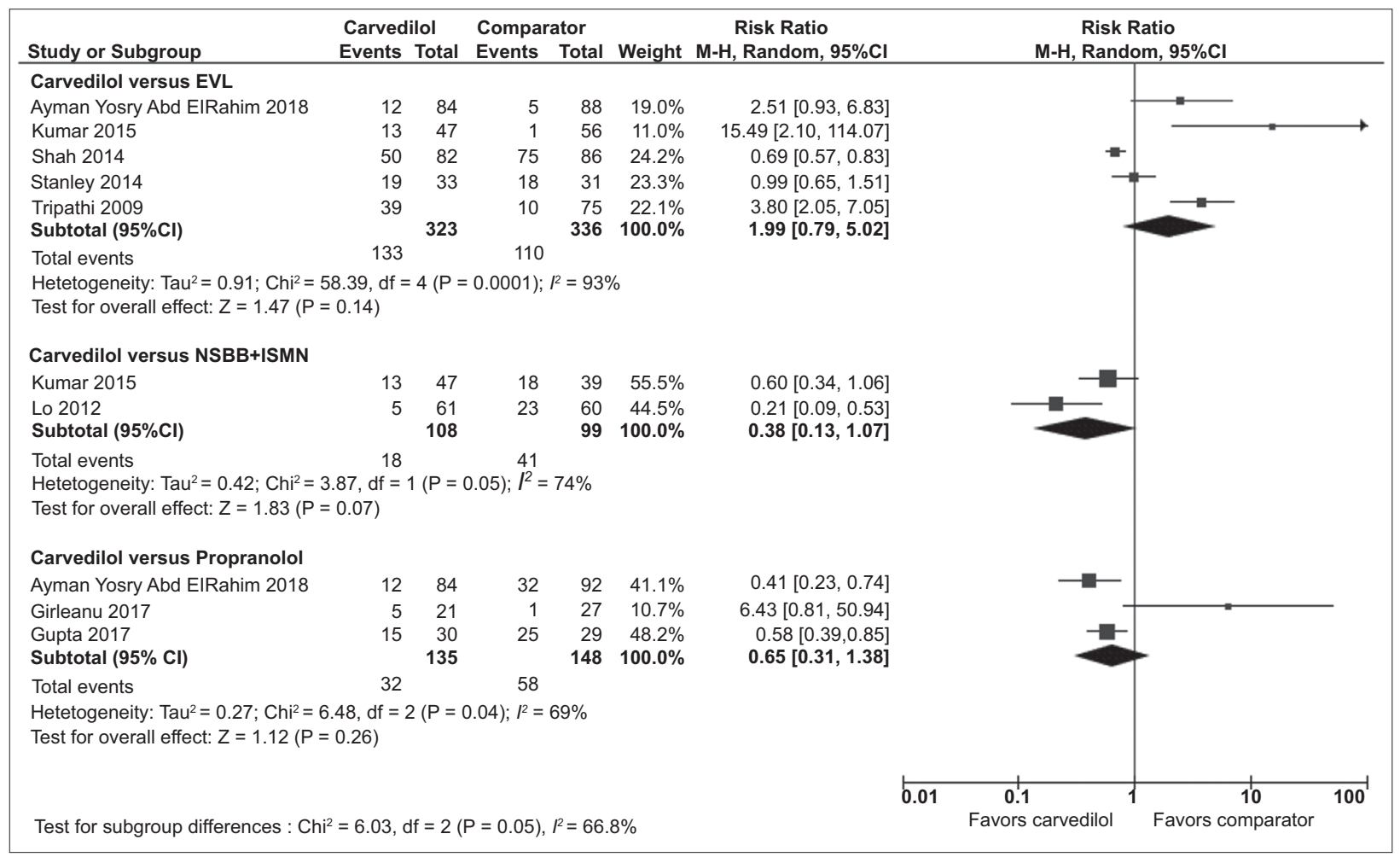

Figure 7 Risk ratio for incidence of any adverse event

CI, confidence interval; EVL, endoscopic variceal ligation; NSBB, non-selective beta-blocker; ISMN, isosorbide-5-mononitrate; M-H, Mantel-Haenszel

heterogeneity, especially in the analysis of any AE, probably due to the inconsistent and poor reporting of AEs. It is worth mentioning that only 1 trial [31] provided a definition for both serious and any AE, while an additional trial [32] provided a definition for serious AE only. The dose of carvedilol was not reported in several trials and, when provided, it differed among trials. Carvedilol-related adverse events, such as systemic hypotension, appear to be dose-dependent. This adds an extra dimension to the increased heterogeneity in the analysis of AEs. Finally, the small-study effect could not be evaluated because of the limited number of trials, while publication bias cannot be excluded. 


\begin{tabular}{|c|c|c|c|c|c|c|c|c|c|}
\hline \multirow[b]{2}{*}{ Study or Subgroup } & \multicolumn{2}{|c|}{ Carvedilol } & \multicolumn{2}{|c|}{ Comparator } & \multirow[b]{2}{*}{ Weight } & \multirow{2}{*}{$\begin{array}{l}\text { Risk Ratio } \\
\text { M-H, Random, } 95 \% \mathrm{Cl}\end{array}$} & \multirow{2}{*}{\multicolumn{2}{|c|}{$\begin{array}{c}\text { Risk Ratio } \\
\text { M-H, Random, } 95 \% \mathrm{Cl}\end{array}$}} & \\
\hline & Events & Total & Events & Total & & & & & \\
\hline \multicolumn{10}{|c|}{ Carvedilol versus EVL } \\
\hline Shah 2014 & 2 & 82 & 0 & 86 & $16.5 \%$ & $5.24[0.26,107.55]$ & & & \\
\hline Stanley 2014 & 5 & 33 & 0 & 31 & $18.0 \%$ & $10.35[0.60,179.79]$ & & & \\
\hline Tripathi 2009 & 10 & 77 & 8 & 75 & $65.5 \%$ & $1.22[0.51,2.92]$ & & & \\
\hline Subtotal $(95 \% \mathrm{Cl})$ & & 192 & & 192 & $100.0 \%$ & $2.28[0.59,8.84]$ & & & \\
\hline Total events & 17 & & 8 & & & & & & \\
\hline \multicolumn{10}{|c|}{$\begin{array}{l}\text { Hetetogeneity: } \text { Tau }^{2}=0.53 ; \mathrm{Chi}^{2}=2.84, \mathrm{df}=2(P=0.24) ; l^{2}=30 \% \\
\text { Test for overall effect: } Z=1.19(P=0.23)\end{array}$} \\
\hline \multicolumn{10}{|c|}{ Carvedilol versus Propranolol } \\
\hline Girleanu 2017 & 2 & 21 & 1 & 27 & $64.8 \%$ & $2.57[0.25,26.47]$ & & & \\
\hline Gupta 2017 & 1 & 30 & 0 & 29 & $35.2 \%$ & $2.90[0.12,68.50]$ & & - & \\
\hline Subtotal $(95 \% \mathrm{Cl})$ & & 51 & & 56 & $100.0 \%$ & $2.68[0.41,17.53]$ & & & \\
\hline Total events & 3 & & 1 & & & & & & \\
\hline \multicolumn{10}{|c|}{ Hetetogeneity: $\mathrm{Tau}^{2}=0.00 ; \mathrm{Chi}^{2}=0.00, \mathrm{df}=1(\mathrm{P}=0.95) ; I^{2}=0 \%$} \\
\hline \multicolumn{10}{|c|}{ Test for overall effect: $Z=1.03(P=0.30)$} \\
\hline & & & & & & 0.01 & $\begin{array}{c}0.1 \\
0\end{array}$ & $\begin{array}{c}10 \\
\end{array}$ & 100 \\
\hline
\end{tabular}

Figure 8 Risk ratio for incidence of withdrawal due to adverse events CI, confidence interval; EVL, endoscopic variceal ligation; $M-H$, Mantel-Haenszel

Our analyses support the Baveno VI consensus guidelines for portal hypertension, in which carvedilol is considered to be a valid first-line treatment in patients with medium or large size varices and no previous history of variceal bleeding. On the other hand, existing guidelines do not support the use of carvedilol for secondary prophylaxis, given the lack of evidence comparing carvedilol to standard of care. However, we identified 2 small trials in which carvedilol was found to be as efficacious as propranolol in preventing rebleeding after variceal eradication with EVL $[29,30]$. In addition, our review showed that carvedilol improves survival compared with EVL, even though they have a similar effect on the risk of rebleeding. This indicates that carvedilol might have a beneficial impact, not only via a reduction in portal hypertension, but also through other protective properties of NSBBs, such as reduction in bacterial translocation and bacterial infections [35,36]. Although our findings indicate that carvedilol is equally efficacious to EVL or propranolol for the prevention of variceal rebleeding, the small number of participants included in these analyses undermines the certainty of our results. Overall, our evidence supports the use of carvedilol in combination with EVL for secondary prevention. However, the limitations of the available trials (small sample size, short duration of follow up, and unclear risk-of-bias estimation) underline the need for high-quality trials to confirm these initial findings. In the absence of adequate direct evidence, a network meta-analysis evaluating the different therapeutic options of patients on prophylaxis for variceal bleeding could provide a better and more precise insight into this area.

In conclusion, carvedilol is a safe and efficacious treatment option for the primary and secondary prophylaxis of variceal bleeding. In addition, it may also delay variceal progression. However, our confidence in these conclusions is very low, given the imprecision, heterogeneity and potential risk of bias of the available evidence. This underlines the need for adequately powered, high-quality clinical trials.

\section{Summary Box}

\section{What is already known:}

- Carvedilol is a guideline-recommended treatment option for the primary prophylaxis of variceal bleeding

- Carvedilol's efficacy in the context of secondary prevention of variceal bleeding is under consideration

- Randomized controlled trials present data regarding its efficacy and safety

\section{What the new findings are:}

- Carvedilol is equally efficacious to endoscopic variceal ligation (EVL), for both primary and secondary prophylaxis of variceal bleeding

- Very low-quality evidence indicates that carvedilol reduces all-cause mortality compared to EVL in patients with a previous history of variceal bleeding

- Very low-quality evidence suggests that carvedilol is as efficacious as propranolol for the prevention of variceal rebleeding after variceal eradication

\section{References}

1. Meseeha M, Attia M. Esophageal varices. [Updated 2017 Oct 11]. In: StatPearls [Internet]. Treasure Island (FL): StatPearls Publishing; 2018.

2. D’Amico G, De Franchis R; Cooperative Study Group. Upper digestive bleeding in cirrhosis. Post-therapeutic outcome and prognostic indicators. Hepatology 2003;38:599-612. 
3. Haq I, Tripathi D. Recent advances in the management of variceal bleeding. Gastroenterol Rep (Oxf) 2017;5:113-126.

4. Al-Busafi SA, McNabb-Baltar J, Farag A, Hilzenrat N. Clinical manifestations of portal hypertension. Int $J$ Hepatol 2012;2012:203794.

5. North Italian Endoscopic Club for the Study and Treatment of Esophageal Varices. Prediction of the first variceal hemorrhage in patients with cirrhosis of the liver and esophageal varices. A prospective multicenter study. N Engl J Med 1988;319:983-989.

6. D'Amico G, Pagliaro L, Bosch J. The treatment of portal hypertension: a meta-analytic review. Hepatology 1995;22:332-354.

7. Abraldes JG, Villanueva C, Bañares R, et al; Spanish Cooperative Group for Portal Hypertension and Variceal Bleeding. Hepatic venous pressure gradient and prognosis in patients with acute variceal bleeding treated with pharmacologic and endoscopic therapy. J Hepatol 2008;48:229-236.

8. Baiges A, Hernández-Gea V, Bosch J. Pharmacologic prevention of variceal bleeding and rebleeding. Hepatol Int 2018;12:68-80.

9. de Franchis R; Baveno VI Faculty. Expanding consensus in portal hypertension: Report of the Baveno VI Consensus Workshop: Stratifying risk and individualizing care for portal hypertension. J Hepatol 2015;63:743-752.

10. Hobolth L, Møller S, Grønbæk H, Roelsgaard K, Bendtsen F, Feldager Hansen E. Carvedilol or propranolol in portal hypertension? A randomized comparison. Scand J Gastroenterol 2012;47:467-474.

11. Reiberger T, Ulbrich G, Ferlitsch A, et al; Vienna Hepatic Hemodynamic Lab. Carvedilol for primary prophylaxis of variceal bleeding in cirrhotic patients with haemodynamic non-response to propranolol. Gut 2013;62:1634-1641.

12. Moher D, Liberati A, Tetzlaff J, Altman DG; PRISMA Group. Preferred reporting items for systematic reviews and metaanalyses: the PRISMA statement. Ann Intern Med 2009;151:264269, W64.

13. Higgins JPT, Sterne JAC, Savović J, et al. A revised tool for assessing risk of bias in randomized trials. Cochrane Database Syst Rev 2016;10(Suppl 1):29-31.

14. Deeks JJ, Higgins JPT, Altman DG (editors). Chapter 9: Analysing data and undertaking meta-analyses. In: Higgins JPT, Green S (editors). Cochrane Handbook for Systematic Reviews of Interventions Version 5.1.0 (updated March 2011). The Cochrane Collaboration, 2011.

15. Egger M, Davey Smith G, Schneider M, Minder C. Bias in metaanalysis detected by a simple, graphical test. BMJ 1997;315:629-634.

16. Wan X, Wang W, Liu J, Tong T. Estimating the sample mean and standard deviation from the sample size, median, range and/or interquartile range. BMC Med Res Methodol 2014;14:135.

17. Luo D, Wan X, Liu J, Tong T. Optimally estimating the sample mean from the sample size, median, mid-range, and/or midquartile range. Stat Methods Med Res 2018;27:1785-1805.

18. Review Manager (RevMan) [Computer program]. Version [5.3]. Copenhagen: The Nordic Cochrane Centre TCC, 2014.

19. Schünemann H BJ, Guyatt G, Oxman A. GRADE handbook for grading quality of evidence and strength of recommendations (Updated October 2013). The GRADE Working Group, 2013.

20. Agarwala V, Prakash G, Singh R, et al. Evaluation of treatment with carvedilol in comparison to propranolol in primary/secondary prophylaxis of gastroesophageal variceal bleeding. Indian $J$ Gastroenterol 2011;30:A46.
21. Girleanu I, Trifan A, Cojocariu C, et al. Carvedilol versus propranolol effect in the primary prophylaxis of variceal bleeding in cirrhotic patients with portal vein thrombosis. United European Gastroenterol J 2017;5(Suppl 5):A405.

22. Abd ElRahim AY, Fouad R, Khairy M, et al. Efficacy of carvedilol versus propranolol versus variceal band ligation for primary prevention of variceal bleeding. Hepatol Int 2018;12:75-82.

23. Khan MS, Majeed A, Ghauri F, Asghar U, Waheed I. Comparison of carvedilol and esophageal variceal band ligation for prevention of variceal bleed among cirrhotic patients. Pak J Med Health Sci 2017;11:1046-1048.

24. Tripathi D, Ferguson JW, Kochar N, et al. Randomized controlled trial of carvedilol versus variceal band ligation for the prevention of the first variceal bleed. Hepatology 2009;50:825-833.

25. Shah HA, Azam Z, Rauf J, et al. Carvedilol vs. esophageal variceal band ligation in the primary prophylaxis of variceal hemorrhage: a multicentre randomized controlled trial. J Hepatol 2014;60:757-764.

26. Bhardwaj A, Kedarisetty CK, Vashishtha C, et al. Carvedilol delays the progression of small oesophageal varices in patients with cirrhosis: a randomised placebo-controlled trial. Gut 2017;66:18381843.

27. Kumar P, Kumar R, Saxena KN, Misra SP, Dwivedi M. Secondary prophylaxis of variceal hemorrhage: a comparative study of band ligation, carvedilol and propranolol plus isosorbide mononitrate. Indian J Gastroenterol 2015;34(Suppl 1):A54.

28. Smith L, Dickson S, Hayes PC, et al. Multicentre randomised controlled study comparing carvedilol with endoscopic band ligation in the prevention of variceal rebleeding. J Hepatol 2013;58(Suppl 1):S255.

29. Wei Y. The effect of carvedilol vs propranolol in patients with cirrhosis related gastroesophageal varices for secondary prophylaxis: a randomized controlled trial. Hepatol Int 2018;12:S571.

30. Gupta V, Rawat R, Shalimar, Saraya A. Carvedilol versus propranolol effect on hepatic venous pressure gradient at 1 month in patients with index variceal bleed: RCT. Hepatol Int 2017;11:181-187.

31. Lo GH, Chen WC, Wang HM, Yu HC. Randomized, controlled trial of carvedilol versus nadolol plus isosorbide mononitrate for the prevention of variceal rebleeding. J Gastroenterol Hepatol 2012;27:1681-1687.

32. Stanley AJ, Dickson S, Hayes PC, et al. Multicentre randomised controlled study comparing carvedilol with variceal band ligation in the prevention of variceal rebleeding. J Hepatol 2014;61:1014-1019.

33. Li T, Ke W, Sun P, et al. Carvedilol for portal hypertension in cirrhosis: systematic review with meta-analysis. BMJ Open 2016;6:e010902.

34. Zacharias AP, Jeyaraj R, Hobolth L, Bendtsen F, Gluud LL, Morgan MY. Carvedilol versus traditional, non-selective betablockers for adults with cirrhosis and gastroesophageal varices. Cochrane Database Syst Rev 2018;10:CD011510.

35. Thalheimer U, Bosch J, Burroughs AK. How to prevent varices from bleeding: shades of grey-the case for nonselective beta blockers. Gastroenterology 2007;133:2029-2036.

36. Senzolo M, Cholongitas E, Marelli L, Thalheimer U, Patch D, Burroughs AK. The low incidence of bacterial infections could be a protective factor against variceal bleeding per se in hemodynamic responders to propranolol. Am J Gastroenterol 2006; 101:2436-2437. 


\section{Supplementary Material}

Supplementary Table 1 Prisma checklist

\begin{tabular}{llll}
\hline Section/topic & $\#$ & Checklist item & Reported on page \# \\
\hline Title & 1 & Identify the report as a systematic review, meta-analysis, or both. & 1 \\
\hline Title & 2 & $\begin{array}{l}\text { Provide a structured summary including, as applicable: background; } \\
\text { objectives; data sources; study eligibility criteria, participants, } \\
\text { and interventions; study appraisal and synthesis methods; results; } \\
\text { limitations; conclusions and implications of key findings; systematic } \\
\text { review registration number. }\end{array}$ & 3 \\
\hline Structured summary & 3 & $\begin{array}{l}\text { Describe the rationale for the review in the context of what is already } \\
\text { known. }\end{array}$ & $\begin{array}{l}\text { Provide an explicit statement of questions being addressed with } \\
\text { reference to participants, interventions, comparisons, outcomes, and } \\
\text { study design (PICOS). }\end{array}$ \\
\hline Introduction & 4,5 & 4 \\
\hline Rationale & &
\end{tabular}

Methods

\begin{tabular}{|c|c|c|c|}
\hline Protocol and registration & 5 & $\begin{array}{l}\text { Indicate if a review protocol exists, if and where it can be accessed } \\
\text { (e.g., Web address), and, if available, provide registration information } \\
\text { including registration number. }\end{array}$ & 4 \\
\hline Eligibility criteria & 6 & $\begin{array}{l}\text { Specify study characteristics (e.g., PICOS, length of follow up) and } \\
\text { report characteristics (e.g., years considered, language, publication } \\
\text { status) used as criteria for eligibility, giving rationale. }\end{array}$ & 5 \\
\hline Information sources & 7 & $\begin{array}{l}\text { Describe all information sources (e.g., databases with dates of coverage, } \\
\text { contact with study authors to identify additional studies) in the search } \\
\text { and date last searched. }\end{array}$ & 5 \\
\hline Search & 8 & $\begin{array}{l}\text { Present full electronic search strategy for at least one database, including } \\
\text { any limits used, such that it could be repeated. }\end{array}$ & Table S2 \\
\hline Study selection & 9 & $\begin{array}{l}\text { State the process for selecting studies (i.e., screening, eligibility, included } \\
\text { in systematic review, and, if applicable, included in the meta-analysis). }\end{array}$ & 5 \\
\hline Data collection process & 10 & $\begin{array}{l}\text { Describe method of data extraction from reports (e.g., piloted forms, } \\
\text { independently, in duplicate) and any processes for obtaining and } \\
\text { confirming data from investigators. }\end{array}$ & 6 \\
\hline Data items & 11 & $\begin{array}{l}\text { List and define all variables for which data were sought (e.g., PICOS, } \\
\text { funding sources) and any assumptions and simplifications made. }\end{array}$ & 6,7 Table 1 \\
\hline Risk of bias in individual studies & 12 & $\begin{array}{l}\text { Describe methods used for assessing risk of bias of individual studies } \\
\text { (including specification of whether this was done at the study or } \\
\text { outcome level), and how this information is to be used in any data } \\
\text { synthesis. }\end{array}$ & 6 \\
\hline Summary measures & 13 & $\begin{array}{l}\text { State the principal summary measures (e.g., risk ratio, difference in } \\
\text { means). }\end{array}$ & 7 \\
\hline Synthesis of results & 14 & $\begin{array}{l}\text { Describe the methods of handling data and combining results of studies, } \\
\text { if done, including measures of consistency }\left(\text { e.g., } \mathrm{I}^{2}\right) \text { for each meta- } \\
\text { analysis. }\end{array}$ & 7 \\
\hline
\end{tabular}

(Contd...) 
Supplementary Table 1 (Continued)

\begin{tabular}{|c|c|c|c|}
\hline Section/topic & $\#$ & Checklist item & Reported on page \# \\
\hline Risk of bias across studies & 15 & $\begin{array}{l}\text { Specify any assessment of risk of bias that may affect the cumulative } \\
\text { evidence (e.g., publication bias, selective reporting within studies). }\end{array}$ & \\
\hline Additional analyses & 16 & $\begin{array}{l}\text { Describe methods of additional analyses (e.g., sensitivity or subgroup } \\
\text { analyses, meta-regression), if done, indicating which were pre-specified. }\end{array}$ & 7 \\
\hline \multicolumn{4}{|l|}{ Rerults } \\
\hline Study selection & 17 & $\begin{array}{l}\text { Give numbers of studies screened, assessed for eligibility, and included } \\
\text { in the review, with reasons for exclusions at each stage, ideally with a } \\
\text { flow diagram. }\end{array}$ & 8 , Figure 1 \\
\hline Study characteristics & 18 & $\begin{array}{l}\text { For each study, present characteristics for which data were extracted } \\
\text { (e.g., study size, PICOS, follow-up period) and provide the citations. }\end{array}$ & 8 , Table 1 \\
\hline Risk of bias within studies & 19 & $\begin{array}{l}\text { Present data on risk of bias of each study and, if available, any outcome } \\
\text { level assessment (see item 12). }\end{array}$ & 9, Tables S3-S9 \\
\hline Results of individual studies & 20 & $\begin{array}{l}\text { For all outcomes considered (benefits or harms), present, for each } \\
\text { study: (a) simple summary data for each intervention group (b) effect } \\
\text { estimates and confidence intervals, ideally with a forest plot. }\end{array}$ & 9-11, Figures 2-8 \\
\hline Synthesis of results & 21 & $\begin{array}{l}\text { Present results of each meta-analysis done, including confidence } \\
\text { intervals and measures of consistency. }\end{array}$ & $9-11$ \\
\hline Risk of bias across studies & 22 & $\begin{array}{l}\text { Present results of any assessment of risk of bias across studies (see } \\
\text { Item 15). }\end{array}$ & \\
\hline Additional analysis & 23 & $\begin{array}{l}\text { Give results of additional analyses, if done (e.g., sensitivity or subgroup } \\
\text { analyses, meta-regression [see Item 16]). }\end{array}$ & $\begin{array}{l}\text { 10-11, Tables } \\
\text { S10-S21 }\end{array}$ \\
\hline
\end{tabular}

Discussion

\begin{tabular}{|c|c|c|c|}
\hline Summary of evidence & 24 & $\begin{array}{l}\text { Summarize the main findings including the strength of evidence } \\
\text { for each main outcome; consider their relevance to key groups (e.g., } \\
\text { healthcare providers, users, and policy makers). }\end{array}$ & $11-12$ \\
\hline Limitations & 25 & $\begin{array}{l}\text { Discuss limitations at study and outcome level (e.g., risk of bias), and at } \\
\text { review-level (e.g., incomplete retrieval of identified research, reporting } \\
\text { bias). }\end{array}$ & $12-13$ \\
\hline Conclusions & 26 & $\begin{array}{l}\text { Provide a general interpretation of the results in the context of other } \\
\text { evidence, and implications for future research. }\end{array}$ & \\
\hline \multicolumn{4}{|l|}{ Funding } \\
\hline Funding & 27 & $\begin{array}{l}\text { Describe sources of funding for the systematic review and other support } \\
\text { (e.g., supply of data); role of funders for the systematic review. }\end{array}$ & 1 \\
\hline
\end{tabular}

From: Moher D, Liberati A, Tetzlaff J, Altman DG, The PRISMA Group (2009). Preferred Reporting Items for Systematic Reviews and Meta-Analyses: The PRISMA Statement PLoS Med 6(7): e1000097. doi:10.1371/journal.pmed1000097

Supplementary Table 2 Search strategy

Medline via PubMed (Mai 2018)

\begin{tabular}{|c|c|}
\hline$\# 1$ & Carvedilol [tw] \\
\hline$\# 2$ & «carvedilol»[Supplementary Concept] \\
\hline$\# 3$ & Carvedilol \\
\hline$\# 4$ & «carvedilol»[All Fields] \\
\hline$\# 5$ & 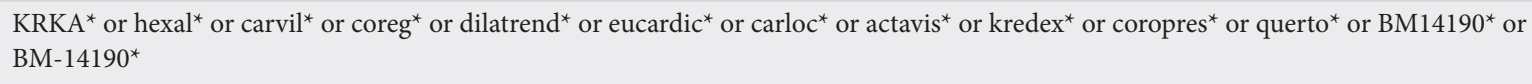 \\
\hline$\# 6$ & OR \#1-5 \\
\hline$\# 7$ & Esophageal and gastric varices [mh] \\
\hline$\# 8$ & Esophageal varices $[\mathrm{mh}]$ \\
\hline
\end{tabular}


Supplementary Table 2 (Continued)

Medline via PubMed (Mai 2018)

\begin{tabular}{|c|c|}
\hline$\# 9$ & Esophageal variceal hemorrhage [mh] \\
\hline$\# 10$ & Variceal hemorrhage $[\mathrm{mh}]$ \\
\hline \#11 & Variceal bleeding $[\mathrm{mh}]$ \\
\hline$\# 12$ & Gastrointestinal bleeding $[\mathrm{mh}]$ \\
\hline$\# 13$ & Gastrointestinal bleeding [tw] \\
\hline$\# 14$ & Oesophageal varices $[\mathrm{mh}]$ \\
\hline \#15 & (Esophag ${ }^{\star}$ OR oesophag $\left.{ }^{\star}\right)$ AND (varic ${ }^{\star}$ OR varix) \\
\hline$\# 16$ & $\left(\right.$ Varix or varic $\left.{ }^{\star}\right)$ AND (bleed ${ }^{\star}$ OR hemorrhage OR prevent ${ }^{\star}$ or prophyla ${ }^{\star}$ ) \\
\hline \#17 & OR \#7-16 \\
\hline$\# 18$ & Randomised controlled trial $[\mathrm{mh}]$ \\
\hline \#19 & Randomized controlled trial [mh] \\
\hline$\# 20$ & Double Blind Method [mh] \\
\hline$\# 21$ & Single Blind Method [mh] \\
\hline$\# 22$ & Random Allocation [mh] \\
\hline$\# 23$ & Clinical trial $[\mathrm{mh}]$ \\
\hline$\# 24$ & $\left(\right.$ singl $^{\star}$ or doub ${ }^{\star}$ or treb ${ }^{\star}$ or tripl $\left.{ }^{\star}\right)$ AND (blind or mask) $[\mathrm{tw}]$ \\
\hline$\# 25$ & Clinical trial phase i $[\mathrm{tw}]$ \\
\hline$\# 26$ & Clinical trial phase ii [tw] \\
\hline$\# 27$ & Clinical trial phase iii $[\mathrm{tw}]$ \\
\hline$\# 28$ & Clinical trial phase iv $[\mathrm{tw}]$ \\
\hline$\# 29$ & Controlled clinical trial $[\mathrm{tw}]$ \\
\hline$\# 30$ & Randomized controlled trial $[\mathrm{tw}]$ \\
\hline$\# 31$ & Randomised controlled trial $[\mathrm{tw}]$ \\
\hline \#32 & Multicenter study $[\mathrm{tw}]$ \\
\hline \#33 & Clinical trial $[\mathrm{tw}]$ \\
\hline \#34 & Randomly allocated $[\mathrm{tw}]$ \\
\hline \#35 & $\left(\right.$ Crossover $^{*}$ or cross over $\left.^{*}\right)[\mathrm{tw}]$ \\
\hline \#36 & Cross-over studies [mh] \\
\hline$\# 37$ & OR \#18-36 \\
\hline \#38 & $\# 6$ and \#17 and \#37 \\
\hline
\end{tabular}

Embase via Ovid (Mai 2018)

\begin{tabular}{ll}
\hline$\# 1$ & carvedilol/ \\
$\# 2$ & carvedilol.mp. \\
$\# 3$ & $\begin{array}{l}\text { KRKA }^{*} \text { or hexal } \\
\text { BM-14190* } \text { or carvil }{ }^{*} \text { or } \text { coreg }^{*} \text { or dilatrend }\end{array}$ \\
$\# 4$ & OR\# or eucardic $^{*}$ or carloc \\
$\# 5$ & Esophagus varices/ \\
$\# 6$ & exp esophagus varices/ \\
$\# 7$ & esophageal varices.mp. \\
\hline 8 & esophageal variceal hemorrhage.mp. \\
\hline
\end{tabular}


Supplementary Table 2 (Continued)

Medline via PubMed (Mai 2018)

\begin{tabular}{|c|c|}
\hline$\# 9$ & variceal hemorrhage.mp. \\
\hline$\# 10$ & variceal bleeding.mp. \\
\hline$\# 11$ & gastrointestinal bleeding/ \\
\hline$\# 12$ & gastrointestinal bleeding.mp. \\
\hline$\# 13$ & oesophageal varices/ \\
\hline$\# 14$ & ((esophag\$ or oesophag\$) and (varic\$ or varix)).mp. \\
\hline$\# 15$ & ((varix or varic\$) and (bleed\$ or hemorrhage or prevent\$ or prophyla\$)).mp. \\
\hline$\# 16$ & Esophagus varices/ \\
\hline$\# 17$ & OR\# 5-17 \\
\hline$\# 18$ & randomized controlled trial/ \\
\hline \#19 & controlled clinical study/ \\
\hline$\# 20$ & randomised controlled trial/ \\
\hline$\# 21$ & single blind procedure/ \\
\hline$\# 22$ & Double Blind Procedure/ \\
\hline$\# 23$ & crossover procedure/ \\
\hline$\# 24$ & randomi?ed controlled trial\$.mp. \\
\hline$\# 25$ & Rct.mp. \\
\hline$\# 26$ & random allocation.mp. \\
\hline$\# 27$ & single blind $\$ . m p$ \\
\hline$\# 28$ & double blind\$.mp. \\
\hline$\# 29$ & triple blind\$.mp. \\
\hline$\# 30$ & $(($ singl\$ or doub\$ or treb\$ or tripl\$) and (blind or mask)).mp. \\
\hline$\# 31$ & (crossover\$ or cross over\$).mp. \\
\hline$\# 32$ & OR\#18-31 \\
\hline$\# 33$ & $\# 4$ and \#17 and \#32 \\
\hline
\end{tabular}

Cochrane Central Register of Controlled Trials (Mai 2018)

\begin{tabular}{ll}
\hline$\# 1$ & Carvedilol \\
$\# 2$ & $\begin{array}{l}\text { KRKA }^{*} \text { or hexal } \\
\text { BM- } 14190^{*}\end{array}$ \\
$\# 3$ & $\# 1$ OR $\# 2$ \\
$\# 4$ & (Esophageal or oesophageal) and (varices) \\
$\# 5$ & (Varix or varices) and (bleeding or hemorrhage or prevention or prophylaxis) \\
$\# 6$ & MeSH descriptor: [Esophageal and Gastric Varices] explode all trees \\
$\# 7$ & MeSH descriptor: [Gastrointestinal Hemorrhage] explode all trees \\
$\# 8$ & $\# 4$ or $\# 5$ or $\# 6$ or $\# 7$ \\
$\# 9$ & $\# 3$ and $\# 8$ \\
\hline
\end{tabular}


Supplementary Table 3 Risk of bias assessment for variceal bleeding

\begin{tabular}{|c|c|c|c|c|c|c|}
\hline Study & $\begin{array}{l}\text { Randomization } \\
\text { process }\end{array}$ & $\begin{array}{l}\text { Deviations from intended } \\
\text { interventions }\end{array}$ & $\begin{array}{l}\text { Missing } \\
\text { outcome data }\end{array}$ & $\begin{array}{l}\text { Measurement } \\
\text { of the outcome }\end{array}$ & $\begin{array}{l}\text { Selection of } \\
\text { reported results }\end{array}$ & Overall bias \\
\hline \multicolumn{7}{|l|}{ Primary prophylaxis } \\
\hline Agarwala et al 2011 [20] & Some concerns & Some concerns & Low & Low & Some concerns & High \\
\hline Girleanu et al 2011 [21] & Some concerns & Some concerns & Low & Low & Low & Some concerns \\
\hline Khan et al 2017 [23] & Some concerns & Low & Low & Low & Low & Some concerns \\
\hline Tripathi et al 2009 [24] & Low & Low & Low & Low & Low & Low \\
\hline Shah et al 2014 [25] & Low & Low & Low & Low & Low & Low \\
\hline $\begin{array}{l}\text { Ayman Yosry Abd } \\
\text { ElRahim et al } 2017 \text { [22] }\end{array}$ & Some concerns & Some concerns & High & Low & Low & High \\
\hline \multicolumn{7}{|l|}{ Secondary prophylaxis } \\
\hline Kumar et al 2015 [27] & Some concerns & Some concerns & Some concerns & Low & Low & High \\
\hline Smith et al 2013 [28] & Some concerns & Some concerns & Some concerns & Low & Low & High \\
\hline Wei et al 2018 [29] & Low & Some concerns & Some concerns & Low & Low & Some concerns \\
\hline Gupta et al 2016 [30] & Low & Some concerns & Some concerns & Low & Low & Some concerns \\
\hline Lo et al 2012 [31] & Low & Low & Low & Low & Low & Low \\
\hline Stanley et al 2014 [32] & Low & Low & High & Low & Low & High \\
\hline
\end{tabular}

Supplementary Table 4 Risk of bias assessment for all-cause mortality

\begin{tabular}{|c|c|c|c|c|c|c|}
\hline Study & $\begin{array}{l}\text { Randomization } \\
\text { process }\end{array}$ & $\begin{array}{l}\text { Deviations from } \\
\text { intended interventions }\end{array}$ & $\begin{array}{l}\text { Missing } \\
\text { outcome data }\end{array}$ & $\begin{array}{l}\text { Measurement } \\
\text { of the outcome }\end{array}$ & $\begin{array}{l}\text { Selection of } \\
\text { reported results }\end{array}$ & Overall bias \\
\hline
\end{tabular}

Primary prophylaxis

\begin{tabular}{|c|c|c|c|c|c|c|}
\hline Girleanu et al 2017 [21] & Some concerns & Some concerns & Low & Low & Low & Some concerns \\
\hline Shah et al 2014 [25] & Low & Low & Low & Low & Low & Low \\
\hline Tripathi et al 2009 [24] & Low & Low & Low & Low & Low & Low \\
\hline Bhardwaj et al 2017 [26] & Low & Low & Low & Low & Low & Low \\
\hline
\end{tabular}

Secondary prophylaxis

\begin{tabular}{lllllll}
\hline Stanely et al 2014 [32] & Low & Low & High & Low & Low & High \\
Lo et al 2012 [31] & Low & Low & Low & Low & Low & Low \\
Kumar et al 2015 [27] & Some concerns & Some concerns & Some concerns & Low & Low & High \\
Smith et al 2013 [28] & Some concerns & Some concerns & Some concerns & Low & Low & High \\
\hline
\end{tabular}

$\underline{\text { Supplementary Table } 5 \text { Risk of bias assessment for bleeding related mortality }}$

\begin{tabular}{|c|c|c|c|c|}
\hline Study & $\begin{array}{l}\text { Randomization } \\
\text { process }\end{array}$ & $\begin{array}{l}\text { Deviations from intended } \\
\text { interventions }\end{array}$ & $\begin{array}{l}\text { Missing outcome } \\
\text { data }\end{array}$ & $\begin{array}{l}\text { Measurement of Selection of Overall bias } \\
\text { the outcome reported results }\end{array}$ \\
\hline
\end{tabular}

Primary prophylaxis

\begin{tabular}{lllllll}
\hline Girleanu et al 2017 [21] & Some concerns & Some concerns & Low & Low & Low & Some concerns \\
Tripathi et al 2009 [24] & Low & Low & Low & Low & Low & Low \\
Shah et al 2014 [25] & Low & Low & Low & Low & Low & Low \\
Bhardwaj et al 2017 [26] & Low & Low & Low & Low & Low & Low \\
\hline
\end{tabular}

Secondary prophylaxis

\begin{tabular}{lllllll}
\hline Stanley et al 2014 [32] & Low & Low & High & Low & Low & High \\
Lo et al 2012 [31] & Low & Low & Low & Low & Low & Low \\
\hline
\end{tabular}


Supplementary Table 6 Risk of bias assessment for all-cause bleeding

\begin{tabular}{|c|c|c|c|c|c|c|}
\hline Study & $\begin{array}{l}\text { Randomization } \\
\text { process }\end{array}$ & $\begin{array}{l}\text { Deviations from } \\
\text { intended interventions }\end{array}$ & $\begin{array}{l}\text { Missing } \\
\text { outcome data }\end{array}$ & $\begin{array}{l}\text { Measurement } \\
\text { of the outcome }\end{array}$ & $\begin{array}{l}\text { Selection of } \\
\text { reported results }\end{array}$ & Overall bias \\
\hline $\begin{array}{l}\text { Stanley et al } 2014 \\
\text { [32] }\end{array}$ & Low & Low & High & Low & Low & High \\
\hline Lo et al 2012 [31] & Low & Low & Low & Low & Low & Low \\
\hline
\end{tabular}

Supplementary Table 7 Risk of bias assessment for variceal progression

\begin{tabular}{lllllll}
\hline Study & $\begin{array}{l}\text { Randomization } \\
\text { process }\end{array}$ & $\begin{array}{l}\text { Deviations from } \\
\text { intended interventions }\end{array}$ & $\begin{array}{l}\text { Missing } \\
\text { outcome data }\end{array}$ & $\begin{array}{l}\text { Measurement } \\
\text { of the outcome }\end{array}$ & $\begin{array}{l}\text { Selection of } \\
\text { reported results }\end{array}$ & $\begin{array}{l}\text { Overall bias } \\
\text { Low }\end{array}$ \\
\hline Bhardwaj et al 2017 [26] & Low & Low & Low & Low & Low & Low \\
\hline
\end{tabular}

$\underline{\text { Supplementary Table } 8 \text { Risk of bias assessment for any adverse event }}$

\begin{tabular}{|c|c|c|c|c|c|c|}
\hline Study & $\begin{array}{l}\text { Randomization } \\
\text { process }\end{array}$ & $\begin{array}{l}\text { Deviations from } \\
\text { intended interventions }\end{array}$ & $\begin{array}{l}\text { Missing } \\
\text { outcome data }\end{array}$ & $\begin{array}{l}\text { Measurement } \\
\text { of the outcome }\end{array}$ & $\begin{array}{l}\text { Selection of } \\
\text { reported results }\end{array}$ & Overall bias \\
\hline $\begin{array}{l}\text { Ayman Yosry Abd } \\
\text { ElRahim et al } 2017 \text { [22] }\end{array}$ & Some concerns & Some concerns & High & Low & Low & High \\
\hline Girleanu et al 2017 [21] & Some concerns & Some concerns & Low & Low & Low & Some concerns \\
\hline Tripathi et al 2009 [24] & Low & Low & Low & Low & Low & Low \\
\hline Shah et al 2014 [25] & Low & Low & Low & Low & Low & Low \\
\hline Stanley et al 2014 [32] & Low & Low & Low & Low & Low & Low \\
\hline Lo et al 2012 [31] & Low & Low & Low & Low & Low & Low \\
\hline Gupta et al 2017 [30] & Low & Some concerns & Low & Low & Low & Some concerns \\
\hline Kumar et al 2015 [27] & Some concerns & Some concerns & Some concerns & Low & Low & High \\
\hline Bhardwaj et al 2017 [26] & Low & Low & Low & Low & Low & Low \\
\hline
\end{tabular}

Supplementary Table 9 Risk of bias assessment for withdrawal due to adverse events

\begin{tabular}{|c|c|c|c|c|c|c|}
\hline Study & $\begin{array}{l}\text { Randomization } \\
\text { process }\end{array}$ & $\begin{array}{l}\text { Deviations from } \\
\text { intended interventions }\end{array}$ & $\begin{array}{l}\text { Missing } \\
\text { outcome data }\end{array}$ & $\begin{array}{l}\text { Measurement } \\
\text { of the outcome }\end{array}$ & $\begin{array}{l}\text { Selection of } \\
\text { reported results }\end{array}$ & Overall bias \\
\hline $\begin{array}{l}\text { Girleanu et al } \\
2017 \text { [21] }\end{array}$ & Some concerns & Some concerns & Low & Low & Low & Some concerns \\
\hline $\begin{array}{l}\text { Tripathi et al } \\
2009 \text { [24] }\end{array}$ & Low & Low & high & Low & Low & High \\
\hline $\begin{array}{l}\text { Shah et al } 2014 \\
\text { [25] }\end{array}$ & Low & Low & Low & Low & Low & Low \\
\hline $\begin{array}{l}\text { Stanley et al } \\
2014[32]\end{array}$ & Low & Low & high & Low & Low & High \\
\hline $\begin{array}{l}\text { Lo et al } 2012 \\
\text { [31] }\end{array}$ & Low & Low & Low & Low & Low & Low \\
\hline $\begin{array}{l}\text { Gupta et al } \\
2017[30]\end{array}$ & Low & Some concerns & Some concerns & Low & Low & Some concerns \\
\hline $\begin{array}{l}\text { Bhardwaj et al } \\
2017 \text { [26] }\end{array}$ & Low & Low & Low & Low & Low & Low \\
\hline
\end{tabular}


Supplementary Table 10 Sensitivity analyses based on risk of bias assessment for variceal bleeding

\begin{tabular}{|c|c|c|c|c|c|}
\hline Sensitivity analysis & Comparison & Trials included & Effect estimate, RR & $95 \% \mathrm{CI}$ & $\mathrm{I}^{2}, \%$ \\
\hline \multicolumn{6}{|l|}{ Primary prophylaxis } \\
\hline \multirow[t]{2}{*}{ Excluding trials at high risk of bias } & Carvedilol vs EVL & 3 & 0.56 & 0.29 to 1.07 & 36 \\
\hline & Carvedilol vs PPL & 1 & 0.96 & 0.24 to 3.85 & $\mathrm{NE}$ \\
\hline \multicolumn{6}{|l|}{ Secondary prophylaxis } \\
\hline \multirow[t]{3}{*}{ Excluding trials at high risk of bias } & Carvedilol vs EVL & \multicolumn{4}{|c|}{ All trials were at high risk of bias } \\
\hline & Carvedilol vs NSBB+ISMN & 1 & 1.17 & 0.80 to 1.72 & $\mathrm{NE}$ \\
\hline & Carvedilol vs PPL & 2 & 0.39 & 0.15 to 1.03 & 0 \\
\hline
\end{tabular}

RR, risk ratio; CI, confidence interval; EVL, esophageal variceal ligation; PPL, propranolol; NSBB, non-selective beta blocker; ISMN, isosorbide-5-mononitrate; NE, not estimable

Supplementary Table 11 Sensitivity analyses based on risk of bias assessment for all-cause mortality

\begin{tabular}{|c|c|c|c|c|c|}
\hline Sensitivity analysis & Comparison & Trials included & Effect estimate, RR & $95 \% \mathrm{CI}$ & $\mathrm{I}^{2}, \%$ \\
\hline \multicolumn{6}{|l|}{ Primary prophylaxis } \\
\hline \multirow[t]{2}{*}{ Excluding trials at high risk of bias } & Carvedilol vs EVL & 2 & 1.06 & 0.75 to 1.50 & 0 \\
\hline & Carvedilol vs PPL & 1 & 1.07 & 0.38 to 3.03 & $\mathrm{NE}$ \\
\hline
\end{tabular}

Secondary prophylaxis

\begin{tabular}{llccc}
\hline Excluding trials at high risk of bias & Carvedilol vs EVL & \multicolumn{2}{c}{ All trials were at high risk of bias } \\
& Carvedilol vs NSBB+ISMN & 1 & 0.87 & 0.48 to 1.57 \\
\hline
\end{tabular}

RR, risk ratio; CI, confidence interval; EVL, esophageal variceal ligation; PPL, propranolol; NSBB, non-selective beta blocker; ISMN, isosorbide-5-mononitrate; NE, not estimable

Supplementary Table 12 Sensitivity analyses based on risk of bias assessment for bleeding-related mortality

\begin{tabular}{|c|c|c|c|c|c|}
\hline Sensitivity analysis & Comparison & Trials included & Effect estimate, RR & $95 \% \mathrm{CI}$ & $I^{2}, \%$ \\
\hline \multicolumn{6}{|l|}{ Primary prophylaxis } \\
\hline \multirow{2}{*}{$\begin{array}{l}\text { Excluding trials at } \\
\text { high risk of bias }\end{array}$} & Carvedilol vs EVL & \multicolumn{4}{|c|}{ No trial was at high risk of bias for this outcome } \\
\hline & Carvedilol vs PPL & \multicolumn{4}{|c|}{ No trial was at high risk of bias for this outcome } \\
\hline \multicolumn{6}{|c|}{ Secondary prophylaxis } \\
\hline \multirow{2}{*}{$\begin{array}{l}\text { Excluding trials at } \\
\text { high risk of bias }\end{array}$} & Carvedilol vs EVL & \multicolumn{4}{|c|}{ Data were available from one trial at high risk of bias for this outcome } \\
\hline & Carvedilol vs NSBB+ISMN & \multicolumn{4}{|c|}{ No trial was at high risk of bias for this outcome } \\
\hline
\end{tabular}


Supplementary Table 13 Sensitivity analyses based on risk of bias assessment for all-cause bleeding

\begin{tabular}{|c|c|c|c|c|c|}
\hline Sensitivity analysis & Comparison & Trials included & Effect estimate, RR & $95 \% \mathrm{CI}$ & $\mathrm{I}^{2}, \%$ \\
\hline \multicolumn{6}{|l|}{ Secondary prophylaxis } \\
\hline \multirow{2}{*}{$\begin{array}{l}\text { Excluding trials at high } \\
\text { risk of bias }\end{array}$} & Carvedilol vs EVL & \multicolumn{4}{|c|}{ Data were available from one trial at high risk of bias for this outcome } \\
\hline & Carvedilol vs NSBB+ISMN & \multicolumn{4}{|c|}{ No trial was at high risk of bias for this outcome } \\
\hline
\end{tabular}

RR, risk ratio; CI, confidence interval; EVL, esophageal variceal ligation, NSBB, non-selective beta blocker, ISMN, isosorbide-5-mononitrate

Supplementary Table 14 Subgroup analysis for variceal bleeding based on the duration of follow up

\begin{tabular}{|c|c|c|c|c|c|}
\hline Subgroup & Comparison & Trials included & Effect estimate, RR & $95 \% \mathrm{CI}$ & $\mathrm{I}^{2}, \%$ \\
\hline \multicolumn{6}{|l|}{ Primary prophylaxis } \\
\hline \multirow[t]{2}{*}{ Trials with $\leq 12$ months of follow up } & Carvedilol vs NSBBs & 2 & 0.66 & 0.13 to 3.40 & 81 \\
\hline & Carvedilol vs EVL & 2 & 0.77 & 0.19 to 3.02 & 81 \\
\hline \multirow[t]{2}{*}{ Trials with $>12$ months of follow up } & Carvedilol vs NSBBs & 1 & 0.96 & 0.24 to 3.85 & NE \\
\hline & Carvedilol vs EVL & 2 & 0.70 & 0.27 to 1.82 & 54 \\
\hline Secondary prophylaxis & \multicolumn{5}{|c|}{ Unable to perform subgroup analysis } \\
\hline
\end{tabular}

RR, risk ratio; CI, confidence interval; EVL, esophageal variceal ligation; NSBBs, non-selective beta clockers; NE, not estimable

Supplementary Table 15 Sensitivity analyses based on risk of bias assessment for any adverse event

\begin{tabular}{|c|c|c|c|c|c|}
\hline Sensitivity analysis & Comparison & Trials included & Effect estimate, RR & $95 \% \mathrm{CI}$ & $\mathrm{I}^{2}, \%$ \\
\hline \multirow[t]{3}{*}{ Excluding trials at high risk of bias } & Carvedilol vs EVL & 2 & 0.79 & 0.56 to 1.11 & 59 \\
\hline & Carvedilol vs NSBB+ISMN & 1 & 0.21 & 0.09 to 0.53 & $\mathrm{NE}$ \\
\hline & Carvedilol vs PPL & 2 & 1.61 & 0.12 to 21.35 & 84 \\
\hline
\end{tabular}

RR, risk ratio; CI, confidence interval; EVL, esophageal variceal ligation; PPL, propranolol; NSBB, non-selective beta blocker; ISMN, isosorbide-5-mononitrate; NE, not estimable

Supplementary Table 16 Sensitivity analyses based on risk of bias assessment for withdrawal due to adverse events

\begin{tabular}{llccc}
\hline Sensitivity analysis & Comparison & Trials included & Effect estimate, RR & 95\%CI \\
\hline Excluding trials at high risk of bias & Carvedilol vs EVL & 1 & 5.24 & 0.26 to 107.55 \\
& Carvedilol vs PPL & 2 & 2.68 & 0.41 to 17.53 \\
\hline
\end{tabular}

RR, risk ratio; CI, confidence interval; EVL, esophageal variceal ligation; PPL, propranolol; NE, not estimable 

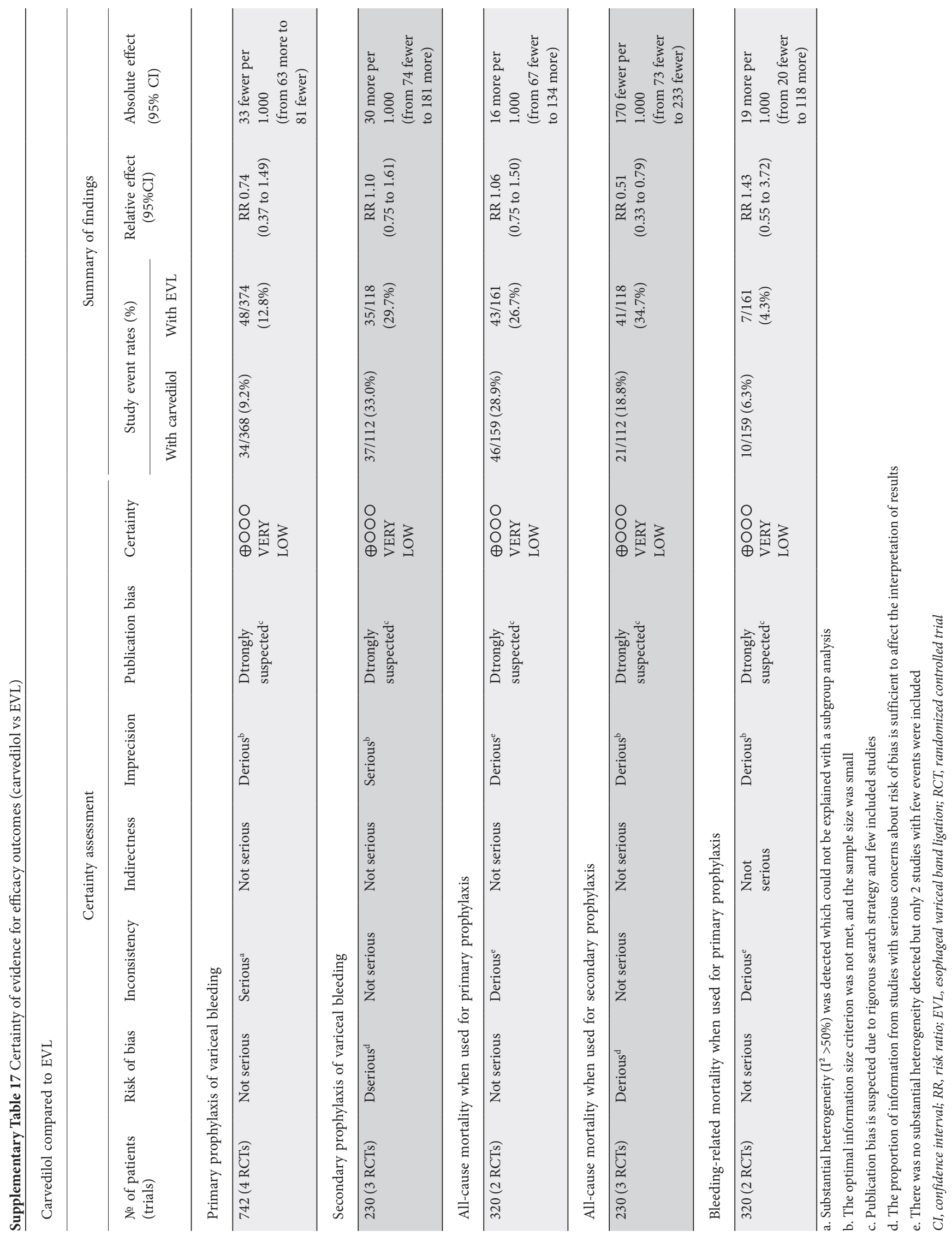


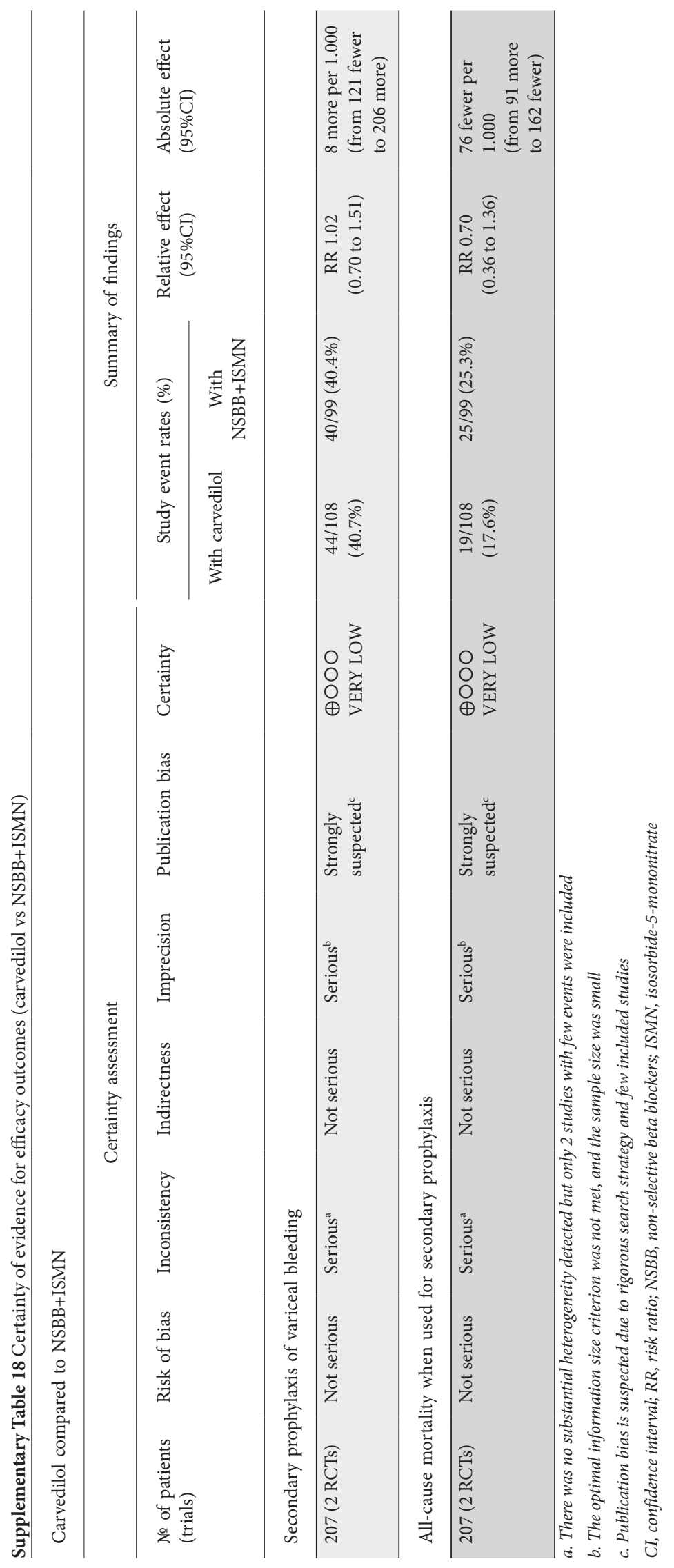




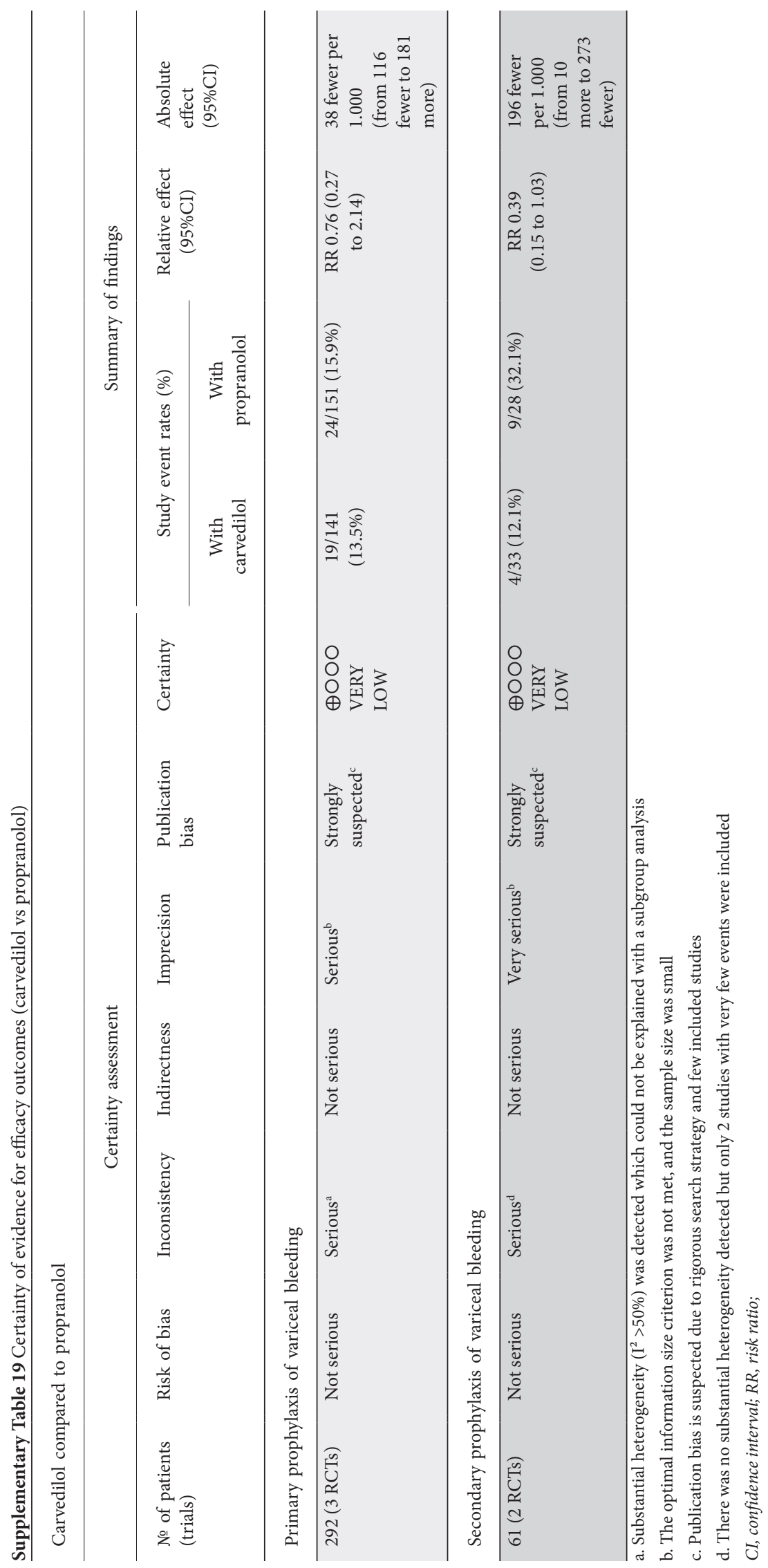




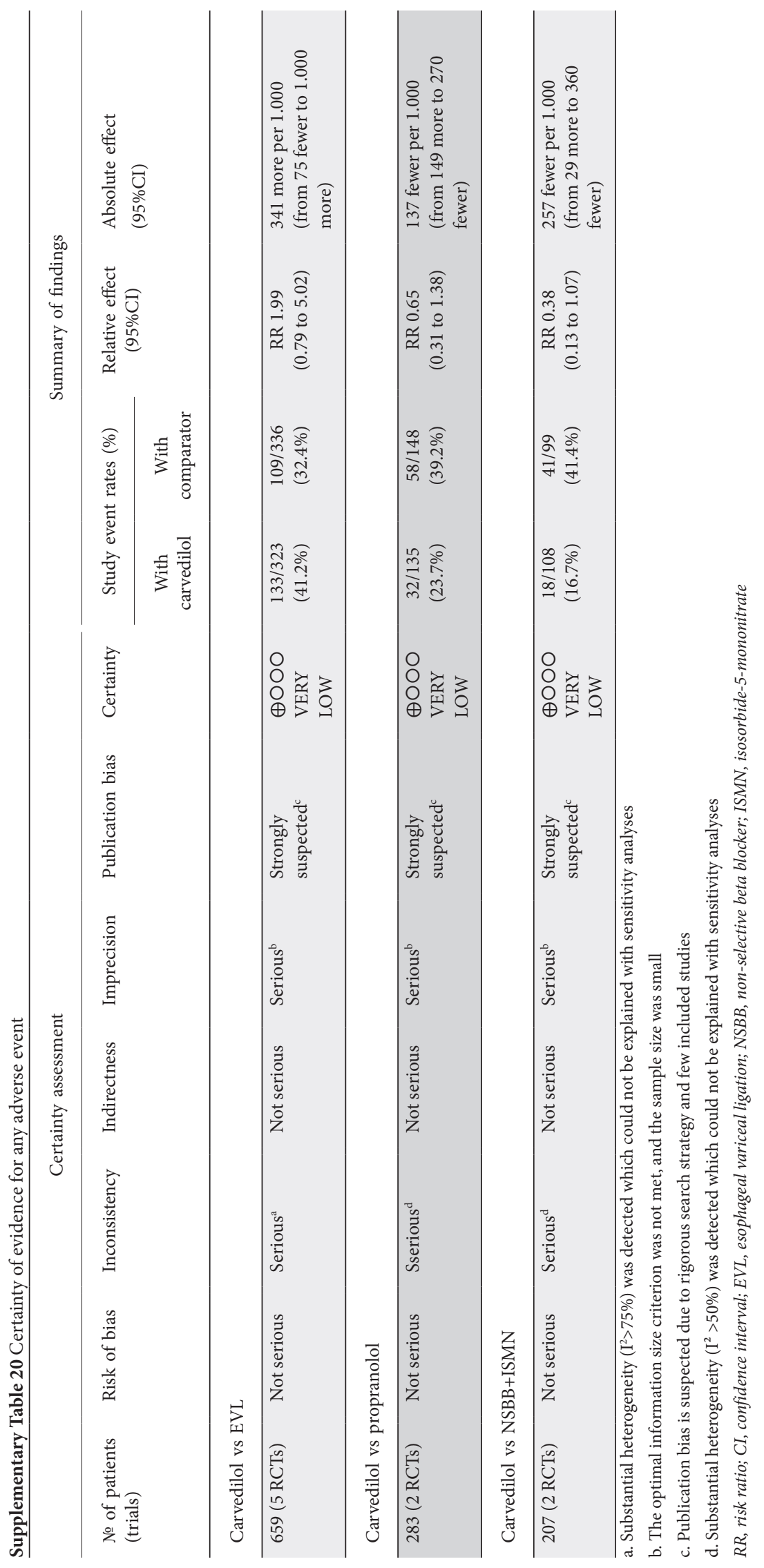




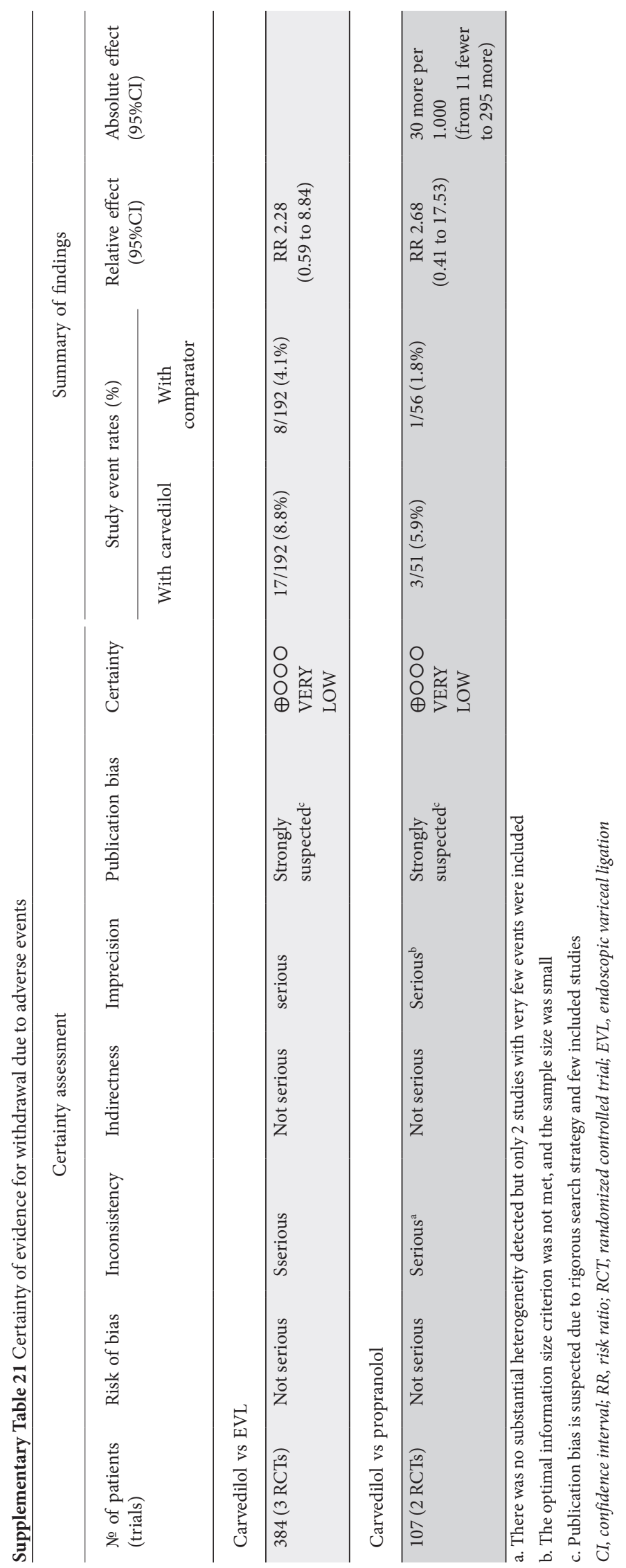

